OPEN ACCESS

Edited by:

Tariq Ezaz,

University of Canberra, Australia

Reviewed by:

Rachel O'Neill,

University of Connecticut, USA

Lukas Kratochvil,

Charles University, Czechia

*Correspondence:

Sally Potter

sally.potter@anu.edu.au

Specialty section:

This article was submitted to Evolutionary and Population Genetics,

a section of the journal

Frontiers in Genetics

Received: 08 December 2016 Accepted: 18 January 2017

Published: 10 February 2017

Citation:

Potter S, Bragg JG, Blom MPK,

Deakin JE, Kirkpatrick M,

Eldridge MDB and Moritz C (2017)

Chromosomal Speciation

in the Genomics Era: Disentangling

Phylogenetic Evolution

of Rock-wallabies. Front. Genet. 8:10.

doi: 10.3389/fgene.2017.00010

\section{Chromosomal Speciation in the Genomics Era: Disentangling Phylogenetic Evolution of Rock-wallabies}

\author{
Sally Potter ${ }^{1,2 *}$, Jason G. Bragg ${ }^{3}$, Mozes P. K. Blom ${ }^{4}$, Janine E. Deakin ${ }^{5}$, \\ Mark Kirkpatrick ${ }^{6}$, Mark D. B. Eldridge ${ }^{2}$ and Craig Moritz ${ }^{1}$
}

${ }^{1}$ Research School of Biology, Australian National University, Acton, ACT, Australia, ${ }^{2}$ Australian Museum Research Institute, Australian Museum, Sydney, NSW, Australia, ${ }^{3}$ National Herbarium of New South Wales, The Royal Botanic Gardens and Domain Trust, Sydney, NSW, Australia, ${ }^{4}$ Department of Bioinformatics and Genetics, Swedish Museum of Natural History, Stockholm, Sweden, ${ }^{5}$ Institute for Applied Ecology, University of Canberra, Bruce, ACT, Australia, ${ }^{6}$ Department of Integrative Biology, University of Texas, Austin, TX, USA

The association of chromosome rearrangements (CRs) with speciation is well established, and there is a long history of theory and evidence relating to "chromosomal speciation." Genomic sequencing has the potential to provide new insights into how reorganization of genome structure promotes divergence, and in model systems has demonstrated reduced gene flow in rearranged segments. However, there are limits to what we can understand from a small number of model systems, which each only tell us about one episode of chromosomal speciation. Progressing from patterns of association between chromosome (and genic) change, to understanding processes of speciation requires both comparative studies across diverse systems and integration of genome-scale sequence comparisons with other lines of evidence. Here, we showcase a promising example of chromosomal speciation in a non-model organism, the endemic Australian marsupial genus Petrogale. We present initial phylogenetic results from exoncapture that resolve a history of divergence associated with extensive and repeated CRs. Yet it remains challenging to disentangle gene tree heterogeneity caused by recent divergence and gene flow in this and other such recent radiations. We outline a way forward for better integration of comparative genomic sequence data with evidence from molecular cytogenetics, and analyses of shifts in the recombination landscape and potential disruption of meiotic segregation and epigenetic programming. In all likelihood, CRs impact multiple cellular processes and these effects need to be considered together, along with effects of genic divergence. Understanding the effects of CRs together with genic divergence will require development of more integrative theory and inference methods. Together, new data and analysis tools will combine to shed light on long standing questions of how chromosome and genic divergence promote speciation.

Keywords: chromosome rearrangement, speciation, rock-wallaby, divergence, genomics 


\section{INTRODUCTION}

Differences in how the genome is packaged - chromosome variation - have long been known to influence how genetic variation is transmitted and redistributed within and among populations (Darlington, 1958; White, 1973). Today, with increasing availability of high quality genome assemblies, the capacity for genome-scale resequencing and the tools of molecular cytogenetics and population- and phylo-genomic analysis, we are returning to a whole-genome perspective on evolution. At the same time, evidence from genome comparisons is revealing that reticulate evolution, including introgression across distantly related species, is far more common in animals than previously thought (Mallet et al., 2016) with implications for gene-tree - species-tree discordance (Edwards et al., 2016). This directs attention to the potential for differing extents of introgression within and outside rearranged regions of the genome (Noor and Bennett, 2009; Crawford et al., 2015).

Here, we revisit the early history of thinking about how chromosomal rearrangements (CRs) affect population and speciation processes. We then highlight a case study that emphasizes how a combined knowledge of genome architecture and genomic sequence divergence is important for understanding the history of CRs in association with speciation and being able to assess whether gene flow is reduced in rearranged regions. Finally, we return to broader themes, considering what combinations of evidence and theory are necessary to gain a holistic understanding of how chromosome change can promote incipient divergence and ultimately translate into species diversification.

\section{Chromosome Change, Population Processes, and Speciation - A Potted History}

Observations on differences in chromosome number and form were some of the earliest data available on genetic differences among species. Inevitably, this led to consideration of whether and how such large-scale restructuring of the genome could cause reproductive isolation - speciation - as well as the role of CRs in adaptive evolution within species (Sturtevant, 1938; Dobzhansky, 1950; Stebbins, 1950; Grant, 1964; White, 1973).

The initial focus on adaptive evolution of CRs was largely for paracentric inversions, and their role in recombination suppression and thus accumulation of linked adaptive genes (Dobzhansky, 1950). More broadly, consideration of how multiple CRs (e.g., reciprocal translocations) could lead to long chains of chromosomes with no recombination lead to concepts of "genetic systems" and their role in maintaining heterozygosity (Darlington, 1958; James, 1982). This thread connecting chromosome organization with adaptive evolution continues today with the proposal that the recombination suppression associated with CRs can promote local adaptation and the accumulation of genetic incompatibilities between species (Navarro and Barton, 2003; Kirkpatrick and Barton, 2006; reviewed in Faria and Navarro, 2010; Ortiz-Barrientos et al., 2016). In one powerful example, Shaw et al. (1986) found that shifts in recombination positions in chromosome heterozygotes of Caledia grasshoppers was associated with hybrid breakdown, and more so than genetic distance per se. Association between range size and rate of inversions in birds also support these models, albeit indirectly (Hooper and Price, 2015).

As evidence of marked differences in chromosome organization among species continued to accumulate, various concepts of chromosomal speciation developed (reviewed by White, 1978; King, 1993). For the most part, these focused on types of CRs that potentially reduce fertility of heterozygotes "sterility models" - because of disruptions of segregation, or meiotic silencing of unsynapsed chromosomes (MSUC) during meiosis (Garagna et al., 2014). The obvious challenge is to explain how a new mutation that reduces the fitness of its heterozygous carrier can survive selection against it, to establish within a local population. Stimulated by the observation that such changes are often seen in taxa that form small isolated populations (e.g., Bush et al., 1977), various models based on strong genetic drift or founder events followed, some analogous to Wright's Shifting Balance Theory of alternating drift and adaptive evolution in metapopulations (Wright, 1982). Such models were immediately controversial, especially when they invoked variants of sympatric speciation (Key, 1968; Futuyma and Mayer, 1980) or rapid fixation in founder populations (Templeton, 1981). This led to strong skepticism of the view that individual chromosome changes, though reduced fertility, could be a primary and common driver of speciation (Walsh, 1982; Coyne et al., 2000; Coyne and Orr, 2004). Nonetheless, in chromosomally diverse butterflies and Drosophila, differences in chromosome number accumulate more rapidly between sympatric than allopatric species and are linked to reinforcing selection for pre-mating isolation (Noor et al., 2001; Lukhtanov et al., 2005; Kandul et al., 2007). An association between speciation and chromosomal evolution was identified in mammals (Bush et al., 1977), and more recently in a diverse genus of lizards, Sceloporus, where a phylogenomic analysis revealed higher speciation rates in clades with extensive Robertsonian fusions (Leaché et al., 2016).

Mechanisms that could promote fixation of chromosome changes despite reduced hybrid fertility include: (i) meiotic drive, (ii) establishment of recombination suppression which facilitates adaptive evolution, and simply, (iii) beneficial effects of CRs on gene expression. (i) Meiotic drive - (segregation distortion) is a powerful evolutionary force that can drive mutations that otherwise reduce fitness to fixation by biased transmission of chromosomes (reviewed in Lindholm et al., 2016; see also Pardo-Manuel de Villena and Sapienza, 2001). Meiotic drive has been observed to favor Robertsonian fusions (metacentric) over unfused (acrocentric) chromosomes in shrews (Wyttenbach et al., 1998; Fedyk and Chętnicki, 2007) but evidence for this in Mus is mixed (Nachman and Searle, 1995; Chmátal et al., 2014). Meiotic drive might also underpin large-scale patterns of chromosome diversity in fish (Yoshida and Kitano, 2012; Molina et al., 2014). Sex chromosomes have been shown to be frequently involved in fusions in fish and amniotes (see Pokorná et al., 2014; Pennell et al., 2015). (ii) Recombination suppression and adaptation - selection to reduce negative effects of chromosomal heterozygosity, including shifts in recombination (chiasma) 
positions, non-homologous pairing and synaptic adjustment. For synapsis to occur during meiosis, chromosomes need to pair to allow crossing over and this process uses the synaptonemal complex. Evidence from a variety of organisms mice (Johannisson and Winking, 1994; Borodin et al., 2005; Manterola et al., 2009), humans (Guichaoua et al., 1986), chickens (Kaelbling and Fechheimer, 1985) and Caenorhabditis elegans (Henzel et al., 2011), highlight that homology of chromosomes is not required to complete this process and synaptic adjustment (reviewed in Zickler and Kleckner, 1999) can overcome issues of non-homology. There is also evidence that this occurs broadly in eutherian mammals between the sex chromosomes (pairing of $\mathrm{X}$ and $\mathrm{Y}$ ), where only a short domain is homologous (pseudo-autosomal region) allowing for non-homologous synapsis (Bergero and Charlesworth, 2009). However, the ability to overcome non-homology depends on a number of factors including the size of the rearrangement, the gene content, the location with respect to centromeres and telomeres and the genetic background (see Torgasheva and Borodin, 2010). This can favor production of balanced gametes for a variety of rearrangements including deletions, insertions, inversions, Robertsonian fusions (Kingswood et al., 1994; Vozdova et al., 2014) and duplications (reviewed in Torgasheva and Borodin, 2010). In addition, recombination suppression may drive adaptive evolution by bringing together advantageous gene combinations (Hoffmann and Rieseberg, 2008; see also Navarro and Barton, 2003). Theory on effects of recombination suppression focuses primarily on inversions (e.g., Kirkpatrick and Barton, 2006) but also considers fusions (Guerrero and Kirkpatrick, 2014) and centric shifts, which may occur via pericentric inversion, three break rearrangements or establishment of neocentromeres, and in the vicinity of centromeres involved in fusion/fissions events (Rieseberg, 2001; Navarro and Barton, 2003). Finally, the simplest possibility is (iii) a beneficial mutation - a rearrangement could generate a beneficial effect of relocating genes into a different regulatory environment, long referred to as position effects (Muller, 1930). As with most mutations, such changes will most often be deleterious (as in humans - Harewood and Fraser, 2014).

The well-known Bateson Dobzhansky Muller (BDM) model (based on work of Bateson, 1909; Dobzhansky, 1936; Muller, 1942) can operate for CRs as it does for genic mutations, avoiding the hybrid-sterility conundrum. Independent chromosome changes arise within isolates, and proceed to fixation by drift or adaptive evolution, followed, on secondary contact, by reduced fertility of heterozygotes for multiple rearrangements (see Coyne and Orr, 2004). Comparative and experimental data on Mus (reviewed in Garagna et al., 2014), Sorex shrews (Polyakov et al., 2011; Horn et al., 2012) and Rhogeessa bats (Baird et al., 2009), appear to be exemplify the BDM process, where the focus is on systems with multiple chromosomal fusions with one or more common arms in different fusion arrangements, i.e., monobrachial homology (Baker and Bickham, 1986).

Putting aside contention over whether chromosomal speciation is common, empirical systems where closely related species differ by multiple, complex CRs are frequently observed (White, 1973; King, 1993; Coyne and Orr, 2004; Dobigny et al.,
2017). However, our current understanding of CRs is largely based on changes that are visible by classical cytology and chromosome banding. With the tools of molecular cytogenetics and high resolution genome sequencing, yet more, often substantial, CRs are being discovered between species thought to have few changes (e.g., human vs. chimpanzee; Prado-Martinez et al., 2013; Farré et al., 2015).

So, how do we revisit these old questions and debates with new theory and empirical evidence? Despite recent advances in chromosomal speciation theory (Kirkpatrick and Barton, 2006; Faria and Navarro, 2010; Kirkpatrick, 2010, 2017; Guerrero et al., 2012b; Guerrero and Kirkpatrick, 2014), more needs to be done to develop inference methods that can exploit genomic comparisons (see Prospectus section). From the empirical perspective, one fruitful approach is to apply genome-scale analyses to systems that exemplify chromosome change among closely related taxa. Sites and Moritz (1987) proposed that models of chromosomal speciation that require strong genetic drift could be tested using simple predictions for reduced genetic polymorphism and elevated divergence, but both the empirical and inference tools available at the time were limiting. This has now changed substantially, with the ability to sequence thousands of loci across populations of any organism and to use coalescent and network methods to infer divergence history (Edwards et al., 2016). The key challenge for recently diverged taxa is to disentangle the effects of retained ancestral polymorphism (incomplete lineage sorting - ILS) from subsequent gene flow. While this remains challenging, the emergence of isolation-with-migration models (Pinho and Hey, 2010) and phylogenetic network methods (Nakhleh, 2013), when combined with genome-scale data, offer some hope. Recent research into the Anopheles system has highlighted the value of genomic data in disentangling ILS from introgression (Fontaine et al., 2015; Wen et al., 2016), as has sliding window analysis of genomes in Xiphophorus fishes (Cui et al., 2013). Whole genomes allow for a suite of new analyses to identify introgression (e.g., using the ABBA-BABA discordance test; Green et al., 2010; Durand et al., 2011; Martin et al., 2015; Nater et al., 2015), but currently there are still limitations based on genome sequencing and alignments, where phasing errors can lead to over-estimation of recombination or mutations (e.g., Qi et al., 2014; Rasmussen et al., 2014). Further, it may be that comparative genome screening alone will not be sufficient to resolve different effects of CRs on divergence (e.g., Suh, 2016; but see Prospectus).

\section{Inferring Divergence Histories of Candidates for Chromosomal Speciation}

To resolve whether CRs initiate divergence or follow genic speciation, we need to focus on recently diverged taxa (Coyne and Orr, 2004). We need to identify organisms that can help address questions in chromosomal speciation and apply integrative tools to them. In particular, cytogenetic and molecular data can be combined to infer the sequence and timing of CRs in systems with complex chromosome change (Faria and Navarro, 2010). This is especially important to interpret signatures of genetic divergence associated with these CRs (Noor and Bennett, 2009). It should 
be reiterated that it remains a formidable challenge to resolve relationships and reticulations among recently separated species (e.g., Leaché et al., 2016).

Several recent comparative studies of species with high quality reference genomes have used extensive resequencing to resolve divergence histories and contrast levels of introgression among recently separated taxa that differ by chromosomal inversions (e.g., Primates - Carbone et al., 2014, Drosophila - Kulathinal et al., 2009; McGaugh and Noor, 2012; Lohse et al., 2015; Anopheles - Wen et al., 2016). There has, however, been mixed support for recombination suppression models (see Faria and Navarro, 2010). By contrast to chromosomal inversions, there have been few genome-scale analyses of closely related taxa with complex Robertsonian fusions. In the Robertsonian fusion races of Mus, increased genetic divergence has been observed at microsatellite loci near the centromeres of fused chromosomes (Franchini et al., 2010; Förster et al., 2016) and simulations of recombination suppression versus hybrid breakdown reveal that hybrid breakdown alone could explain the patterns in $M u s$ from Italy (Giménez et al., 2013). Like Mus, reduced gene flow (higher divergence) is evident within CRs in Sorex shrews (Basset et al., 2006; Yannic et al., 2009).

While analyses of model systems, such as the above, have provided important insights into causes and consequences of CRs, it remains important to extend analyses of effects of chromosome change to systems with distinct genomic features and population structures (Payseur and Rieseberg, 2016). In the following, we present one such example and then conclude with a prospectus for how to advance this and other non-model systems. With this and other such systems, we hope to obtain a greater insight into the processes driving variation in genomic architecture, that lead to divergence and speciation.

\section{CASE STUDY: Petrogale ROCK-WALLABIES}

The rock-wallaby (Petrogale) system has been considered a classical model for chromosomal speciation due to extensive chromosome repatterning, combined with their habitat specialization (rocky environments) which causes populations to be isolated and small (King, 1993). Rock-wallabies are medium sized marsupials (1-12 kg) that inhabit complex rocky areas distributed across continental Australia and some offshore islands, (Eldridge, 2008). A strong propensity for isolation among disjunct rocky habitats (e.g., Pope et al., 1996; Hazlitt et al., 2006) is thought to increase their rate of speciation and contribute to the fixation of novel CRs (Eldridge and Close, 1993). Petrogale includes 17 recognized species corresponding to 23 chromosomal taxa (Supplementary Table 1; Figure 1). This is the most chromosomally diverse genus of marsupials, which in general have a conserved karyotype across all five Australasian and American super-families $(2 n=14$; Rofe and Hayman, 1985; Hayman, 1990; see O’Neill et al., 1999; Graves and Renfree, 2013). Macropodids (kangaroos and wallabies) show variable karyotypes (see O'Neill et al., 1999), but the ancestral macropodid $2 n=22$ karyotype is only found in Petrogale (P. lateralis,
P. persephone, P. rothschildi, and $P$. xanthopus; Eldridge et al., 1992a) and Thylogale (Pademelons). The $2 n=22$ macropodid ancestral karyotype is itself derived from the widespread $2 n=14$ marsupial karyotype by a series of fissions (Rofe, 1979; Hayman, 1990). CRs are extensive across Petrogale, and range from simple to complex. A majority of the rearrangements are Robertsonian fusions, but there is also cytogenetic evidence for inversions and centric shifts (centromeric transpositions) (Eldridge et al., 1989, 1990, 1991, 1992b; Eldridge and Close, 1992, 1993). In addition, the $\mathrm{X}$ chromosome is frequently variable in morphology among taxa and also sometimes within taxa (Eldridge and Close, 1997). The highest chromosomal diversity occurs in groups that are sympatric or parapatric (brachyotis and penicillata groups; Eldridge et al., 1992b; Eldridge and Close, 1993; Figure 1), and these are also the most speciose. This pattern matches the predictions of chromosomal speciation models (see Faria and Navarro, 2010) and the recombination suppression model. This could reflect yet another scenario where fixation rate of chromosomal rearrangements correlates with parapatry and sympatry - suggesting adaptation and divergent selection could be a dominant process driving fixation (e.g., Hooper and Price, 2015).

The brachyotis group of rock-wallabies includes four species and five sub-species distributed across northwestern Australia which have the most complex rearrangements found in Petrogale (Supplementary Table 2) and large amounts of centromeric constitutive heterochromatin not present in other Petrogale (Maynes, 1989; Sharman et al., 1990; Eldridge et al., 1992b; Eldridge and Close, 1993). Within the lateralis group, there are two chromosomal races and three sub-species (Eldridge et al., 1991; Figure 1). These races/sub-species are recently diverged and are distinguished by single autosomal rearrangements or fusions (Eldridge and Close, 1993, 1997; Figure 1). However, the most interesting group are the recently diverged $(\sim 0.5-$ 2.7 mya; Potter et al., 2012a) Queensland penicillata group taxa. Six parapatric species display extensive variation in karyotypes ranging from simple to complex - including fusions, inversions and centric shifts (see Eldridge and Close, 1993). Early research was driven by cytogenetic analyses (reviewed in Eldridge and Close, 1997) and captive breeding experiments that showed evidence of reproductive isolation including infertile male hybrids and reduced fertility of female hybrids (Eldridge and Close, 1992). This resulted in the description of three new species (Eldridge and Close, 1992) and a focus on the role of chromosomal variation in speciation. Meiotic irregularities, including problems with more extensive rearrangements and $\mathrm{X}$-autosome associations have been reported (Close et al., 1996) - patterns also seen in model systems (e.g., Mus). Recent genetic analysis of the penicillata group using microsatellites and mitochondrial DNA (mtDNA) found extensive sharing of alleles between some of the most chromosomally divergent species (Potter et al., 2015). This could be a consequence of introgression or ILS. Further analysis of nuclear markers across the genome is required to assess the genomic divergence between these species and assess if speciation with gene flow is occurring between these taxa, or if more complex interactions between genomic architecture and genic divergence is at play. The 


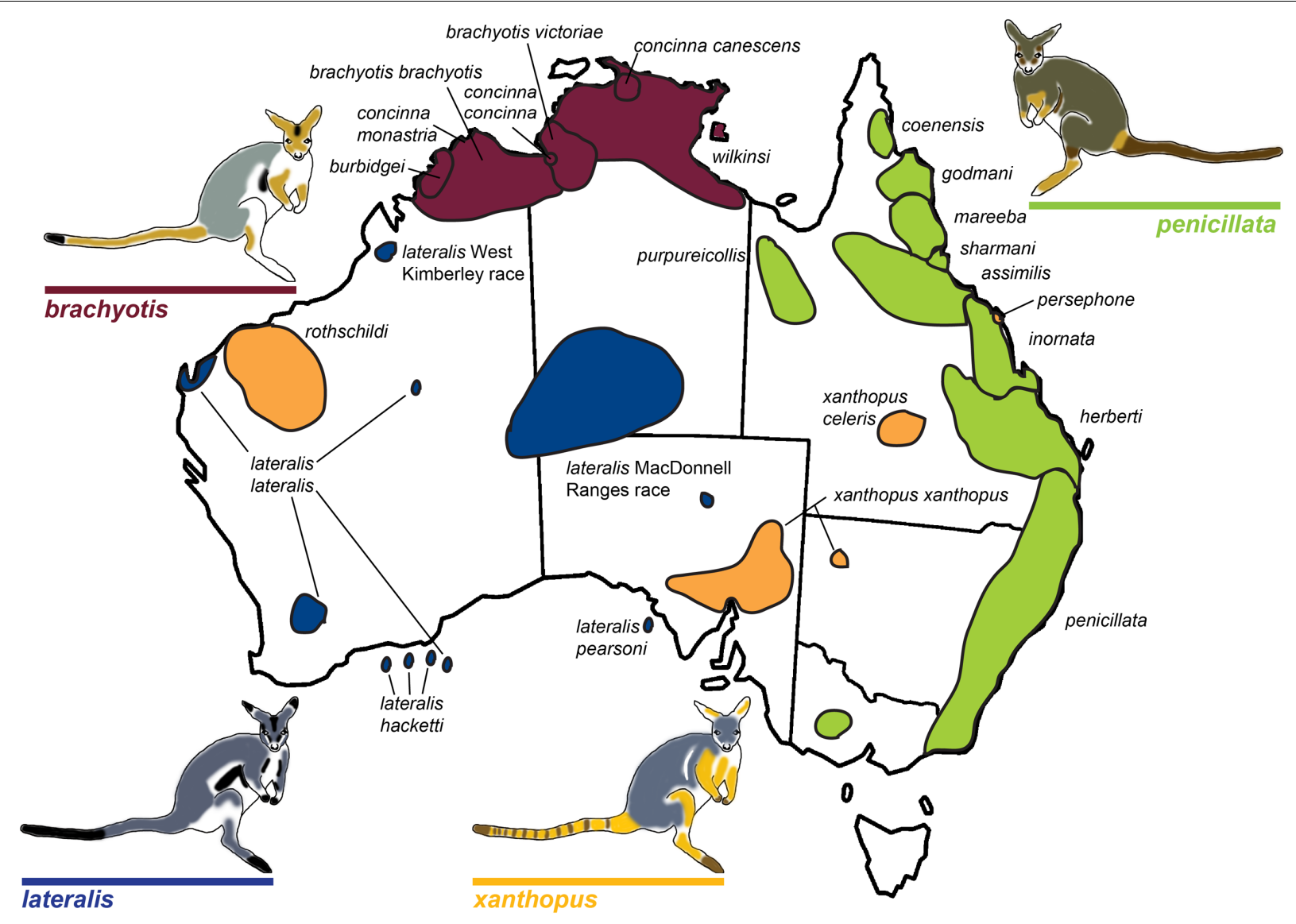

FIGURE 1 | Map of rock-wallaby (Petrogale) taxa distributions across Australia. Map modified from Eldridge and Close (1993). Taxa are colored in accordance with their chromosomal groupings: the brachyotis group = red; the xanthopus group = yellow; the lateralis group = blue; and the penicillata group $=$ green .

characteristics of this genus, specifically their rapid radiation and extensive chromosome variation, make them a valuable model for understanding chromosome evolution and speciation.

Phylogenetic analyses of the rock-wallabies have not previously included representatives of all 23 chromosomal taxa, nor have they been able to resolve phylogenetic relationships, particularly among the more recently evolved species within the penicillata group (Campeau-Péloquin et al., 2001; Potter et al., 2012a). This, in addition to evident homoplasy of rearrangements (see Eldridge and Close, 1993), has precluded tracing the evolution of chromosomal changes. The phylogenetic relationship of $P$. xanthopus and $P$. purpureicollis has also been difficult to resolve (see Eldridge et al., 1991; Eldridge and Close, 1993; Potter et al., 2012a), which has hindered interpreting chromosome evolution as these taxa retain the ancestral chromosome number.

Here, we report results from targeted capture for $\sim 2000$ exons from two individuals per taxon to resolve the relationships across the genus (all supplementary material and methods are outlined in Supplementary Datasheet 1). These data allow us to understand the evolution of chromosomes in this group. In particular, they provide insight into phylogenetic and sequence divergence signals of discordance across the $\mathrm{X}$, rearranged and non-rearranged chromosome arms that could reflect effects of CRs on gene flow (see Supplementary Table 3). We focus on sets of concatenated loci, rather than individual gene trees as individual exons have low phylogenetic resolution at this scale. While it is desirable to use multispecies coalescent approaches (e.g., *BEAST and ASTRAL), such programs are confounded by introgression across non-sister data and are therefore unsuitable for this system (see Solis-Lemus et al., 2016). Hence, we explore multispecies coalescent network approaches that allow for introgression (see below; reviewed in Nakhleh, 2013; Edwards et al., 2016). We expect to find discordant phylogenies and divergence levels between these categories of loci, particularly for the recent radiation of Queensland taxa.

The phylogenetic relationships amongst taxa using the entire dataset of 1961 exons and $\sim 1$ million bp firmly resolves, for the first time, relationships within Petrogale (Figure 2). The brachyotis group with the most extensive chromosomal rearrangements is also phylogenetically basal, which is consistent with previous genetic data (Campeau-Péloquin et al., 2001; Potter et al., 2012a). The xanthopus chromosomal group is paraphyletic. $P$. rothschildi forms the sister taxon to the 
A

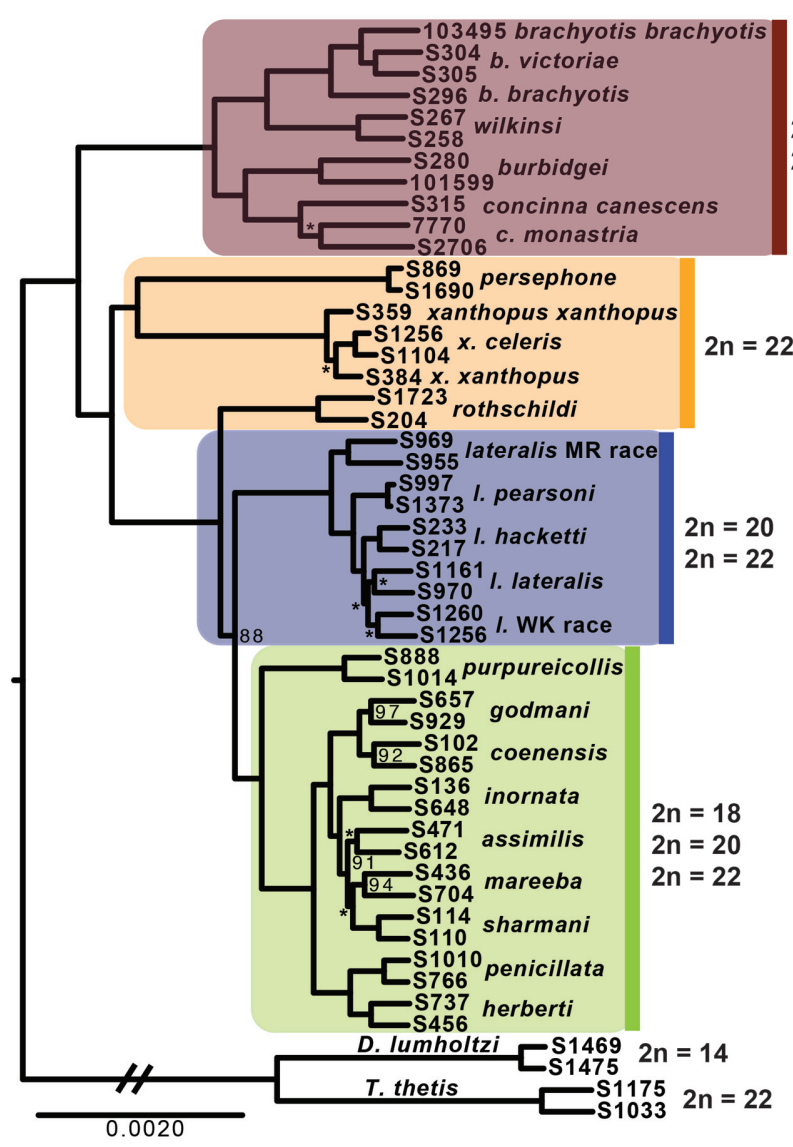

B

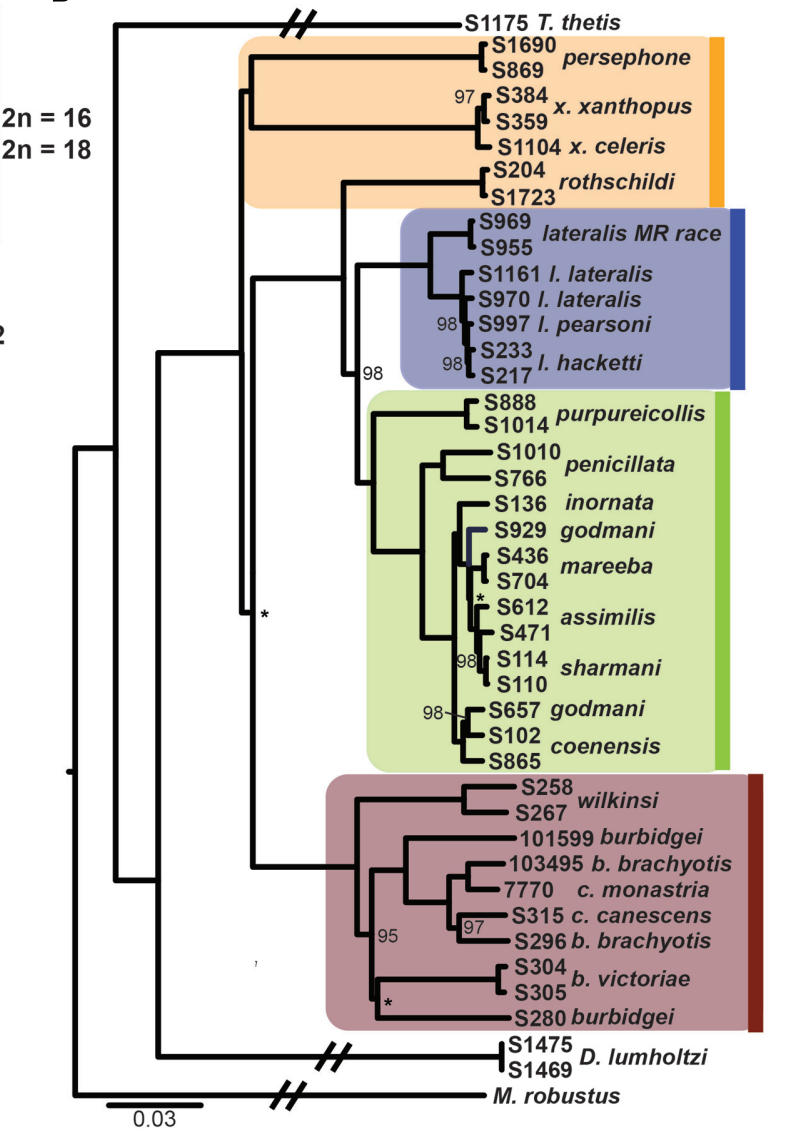

FIGURE 2 | (A) Phylogenetic relationships of rock-wallabies (Petrogale) based on a maximum likelihood analysis of concatenated nuclear data (1961 loci). Bootstrap support $<100 \%$ is outlined on the nodes, ${ }^{*}=<50 \%$; nodes with neither have support of $100 \%$. Four chromosomal groups are highlighted on the phylogeny: the brachyotis group = red; the xanthopus group = yellow; the lateralis group = blue; and the penicillata group = green. Karyotype variation ( $2 n$ ) for each of the four chromosomal groups is highlighted. Dendrolagus lumholtzi (tree kangaroo) and Thylogale thetis (pademelon) are used as outgroups. (B) A maximum likelihood mitochondrial phylogeny of Petrogale based on all mitochondrial coding genes (12 loci). Chromosomal groups are highlighted to match (A), as is bootstrap support.

lateralis and penicillata groups, where as $P$. persephone and $P$. xanthopus form a well supported monophyletic group. There is deep divergence between all three taxa that retain the ancestral karyoptype. The cytogenetically conservative lateralis group has similar branch lengths among taxa to those among species within the more chromosomally diverse penicillata group. Despite recent speciation, each taxon within the lateralis and penicillata groups is monophyletic, albeit with lower support for $P$. lateralis lateralis, $P$. $l$. West Kimberley race and P. assimilis. Relationships amongst some of the most closely related taxa are also not strongly resolved, but we note that monophyly of $P$. mareeba and $P$. sharmani is consistent with their chromosomal evolutionary history, since both share a derived fusion between chromosomes 5 and 10. Although the phylogenetic position of $P$. purpureicollis has been previously unresolved (Sharman et al., 1990; Eldridge et al., 1991; CampeauPéloquin et al., 2001; Potter et al., 2012a), these new data strongly resolve it as sister to the penicillata group. The sub-species of both $P$. brachyotis and $P$. xanthopus (with no known chromosomal differences) did not form monophyletic lineages, suggesting recent divergence or some nuclear gene flow.

Given a well-resolved phylogeny, we can now investigate the history of chromosome change in the genus. Using parsimony mapping of CRs, as identified by G-banding (Eldridge and Close, 1993) we were able to resolve ancestral nodes where rearrangements occurred, in particular a single origin of CR 7a $(\mathrm{a}=$ acrocentric). However, for some chromosomes, we could not distinguish between different hypotheses (see Figure 3; Supplementary Table 2). Apparent multiple independent origins of the $3 \mathrm{a}, 4 \mathrm{a}, 4 \mathrm{sm}(\mathrm{sm}=$ submetacentric $)$ and $5 \mathrm{i}$ ( $i=$ inversion) rearrangements suggest there could be regions of the genome susceptible to rearrangement processes ("hotspots"), which have also been implicated in chromosome change in other macropodids (Bulazel et al., 2007). This highlights the potential for convergent evolution of rearrangements, including chromosomal fusions (e.g., 6 and 10 fusion), inversions and centromere shifts. The alternate hypotheses are multiple reversals to an ancestral chromosome morphology, or the introgression of chromosomes between taxa, but further analysis (e.g., 

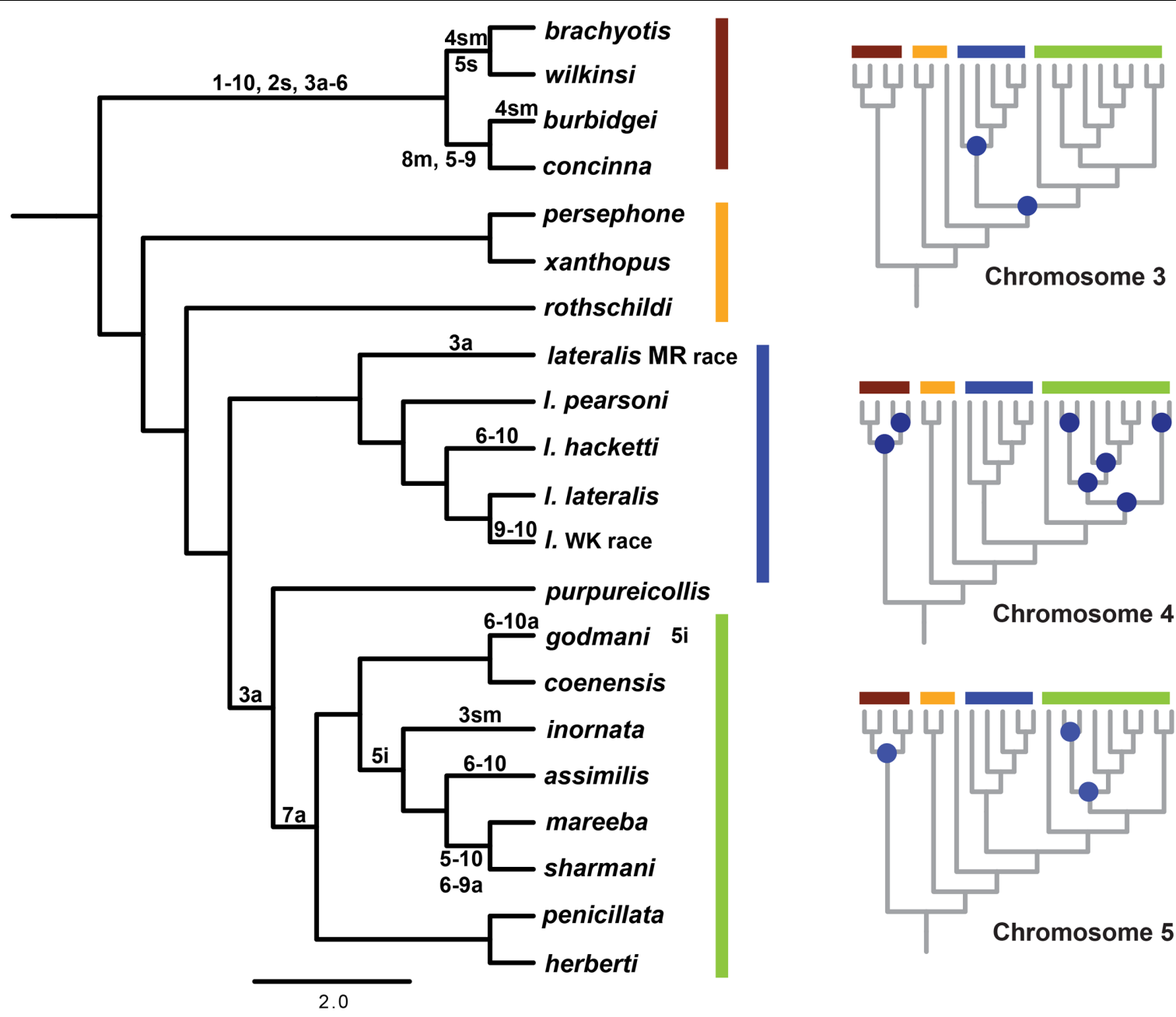

FIGURE 3 | Reconstruction of chromosomal rearrangements based on parsimony analysis for Petrogale using only known chromosomal karyotypes (e.g., no sub-species for $\boldsymbol{P}$. brachyotis, $\boldsymbol{P}$. concinna or $\boldsymbol{P}$. xanthopus). Reconstructions of ancestral karyotypes are highlighted on the main phylogeny and those that could not be resolved for nodes in the phylogeny are indicated in blue for chromosomes 3, 4, and 5. See Supplementary Table 2 for character state matrix. Chromosomal groups are again outlined in color: brachyotis = red; xanthopus = yellow; lateralis = blue; and penicillata = green. Chromosomal rearrangements include: centric shifts, $a=$ acrocentric, $m=$ metacentric, sm = submetacentric; inversions (i); and fusions between two chromosomes (-).

sequencing of breakpoints) is required to distinguish between them. In addition to parallel evolution, the same chromosomes are involved in fusion events in different taxa (e.g., 5, 6, 9, and 10). Cell culture experiments using mitomycin $\mathrm{C}$ to induce centric fusions showed that chromosome 10 fused most frequently (Eldridge and Johnston, 1993). Despite all chromosomes being involved in fusions in this experiment, the higher frequency of chromosome 10 fusions in vitro matches the larger proportion of chromosome 10 being involved in fusions in the wild in Petrogale (five out of eight fusions). This together with higher frequencies of breakpoints from gamma radiation in chromosomes 5, 6 and 10 (Eldridge and Johnston, 1993) further support the notion of a nonrandom process of CR.

Next, we partitioned the sequenced exons into autosomalnon-rearranged ( $N=140$ exons; 75,296 bp), autosomalrearranged ( $N=160$ exons; $36,168 \mathrm{bp}$ ), and the $\mathrm{X}$ chromosome ( $N=21$ exons; 8,951 bp). This approach was motivated by the expectation that autosomes will have less phylogenetic signal than the $\mathrm{X}$ because of their higher gene flow rates and larger $N_{\mathrm{e}}$ (see Supplementary Table 3 for mapped loci). Mean divergence between the four chromosomal groups varies across the $\mathrm{X}$ chromosome, rearranged and non-rearranged autosomes (Figure 4). When accounting for differences in sequence length, we find that the $\mathrm{X}$ has reduced diversity compared with the autosomes, although only slightly compared to the rearranged autosomes. In other mammalian systems (e.g., apes - Nam et al., 2014) several selective sweeps have created large regions of low diversity on the $\mathrm{X}$ chromosome. Assessment of more loci along the $\mathrm{X}$ is necessary to explore if the lower diversity on the $\mathrm{X}$ within Petrogale is associated with selection. The effects of small $N_{\mathrm{e}}$ on the $\mathrm{X}$ will need to be assessed to distinguish between selective sweeps and neutral models of evolution. However, given that sex chromosomes contribute disproportionately to postzygotic isolation in many taxa (e.g., Drosophila, Presgraves, 2008; 


\section{Average Net Divergence between taxa within chromosomal groups}

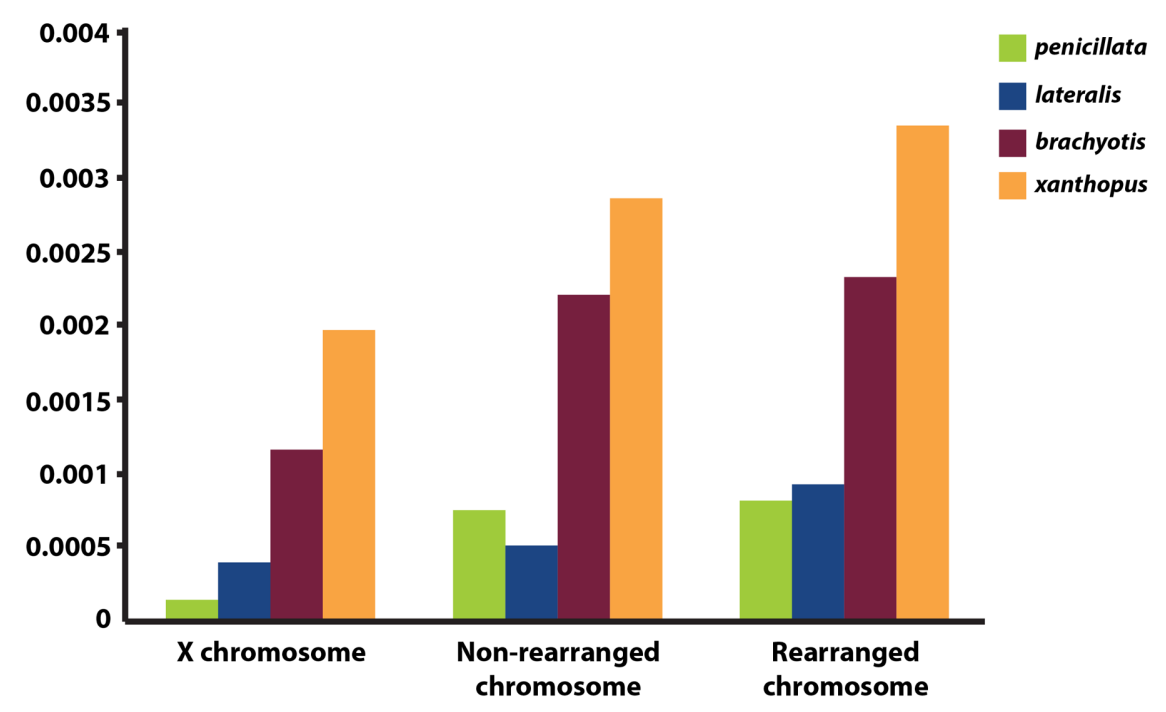

FIGURE 4 | Graph of average net divergence between taxa within each chromosomal group: brachyotis, lateralis, penicillata, and xanthopus. Divergences are estimated for loci on the X chromosome, non-rearranged chromosomes $(2,4,7,8)$ and rearranged chromosomes $(5,6,9,10)$.

Flycatchers, Saether et al., 2007), and evidence of the Petrogale system conforming to Haldane's rule, we would expect more loci on the $\mathrm{X}$ to conform to the true species phylogeny than autosomal loci (as argued by Fontaine et al., 2015).

Rearranged and non-rearranged chromosomes show similar levels of divergence in the brachyotis and penicillata groups, which are among the most chromosomally diverse Petrogale (Figure 5). Conversely, rearranged chromosomes showed the greatest increase in divergence relative to non-rearranged chromosomes in the lateralis group, which has relatively few rearrangements. These observations do not tend to support the hypothesis that CRs are a primary cause of speciation. Instead, the CRs may have fixed when species were already isolated. Alternatively, the existing data may be inadequate to distinguish between these hypotheses. Further work is needed.

We expect clearer phylogenetic resolution in rearranged than in non-rearranged regions of the genome, particularly within the penicillata group (Figure 5). Neither autosomal phylogenetic reconstructions are able to resolve the relationships of the lateralis and penicillata groups. The phylogeny based on rearranged regions does however, separate $P$. herberti and $P$. penicillata from the remaining taxa, as well as $P$. coenensis and $P$. godmani, compared to the non-rearranged chromosomes. Both autosomal phylogenies resolve the brachyotis and xanthopus groups, but the rearranged phylogeny places the xanthopus group as basal instead of the brachyotis group. By contrast, the $\mathrm{X}$ loci resolve nodes deeper in the tree but appears to lack enough information to resolve all of the internal relationships of the lateralis and penicillata groups. The $\mathrm{X}$ however, does generally group individuals of a taxon together, unlike the autosomes (Figure 2).

We then asked how often the individuals sampled from each species formed a monophyletic group for the different subsets of exons. If rearrangements result in reduced introgression, we expect to see higher concordance in concatenated loci from rearranged than non-rearranged chromosome arms. Further, as the $\mathrm{X}$ chromosome is frequently found to be resistant to gene flow, we also expected higher congruence across the X-linked loci. On average, the rearranged chromosomes have greater monophyly of taxa than the non-rearranged for the penicillata group, supporting our hypothesis of higher concordance. We do, however, find the opposite pattern for the lateralis group (Supplementary Table 4). This may be because the lateralis group has fewer rearranged loci. Overall it had lower concordance of monophyletic individuals compared to the penicillata group. The $\mathrm{X}$ chromosome had the greatest average monophyly. This may result from a smaller $N_{\mathrm{e}}$ of the $\mathrm{X}$, faster divergence of the $\mathrm{X}$ (e.g., Charlesworth et al., 1987), or greater divergent selection on the X. The evolution of the sex chromosomes needs further investigation.

Analysis of all mitochondrial coding genes (12 genes; $11,373 \mathrm{bp}$ ), albeit still a single linkage group, reveals some strong conflicts between mitochondrial and nuclear evolutionary history (Figure 2). Previously, it has been highlighted that introgression, retained ancestral polymorphism (or ILS) has resulted in paraphyletic species complexes within both the brachyotis group (see Potter et al., 2012a,b) and the penicillata group (Briscoe et al., 1982; Bee and Close, 1993; Potter et al., 2015). This is the first analysis using all coding genes across the mitochondrial genome, providing the most phylogenetic information and highlight discrepancies to the nuclear phylogeny, in particular - the placement of $P$. persephone and $P$. xanthopus as basal branches; the paraphyly of brachyotis group taxa; and lack of monophyly for $P$. assimilis, $P$. coenensis and $P$. godmani within the penicillata group. These inconsistencies further highlight areas of potential 


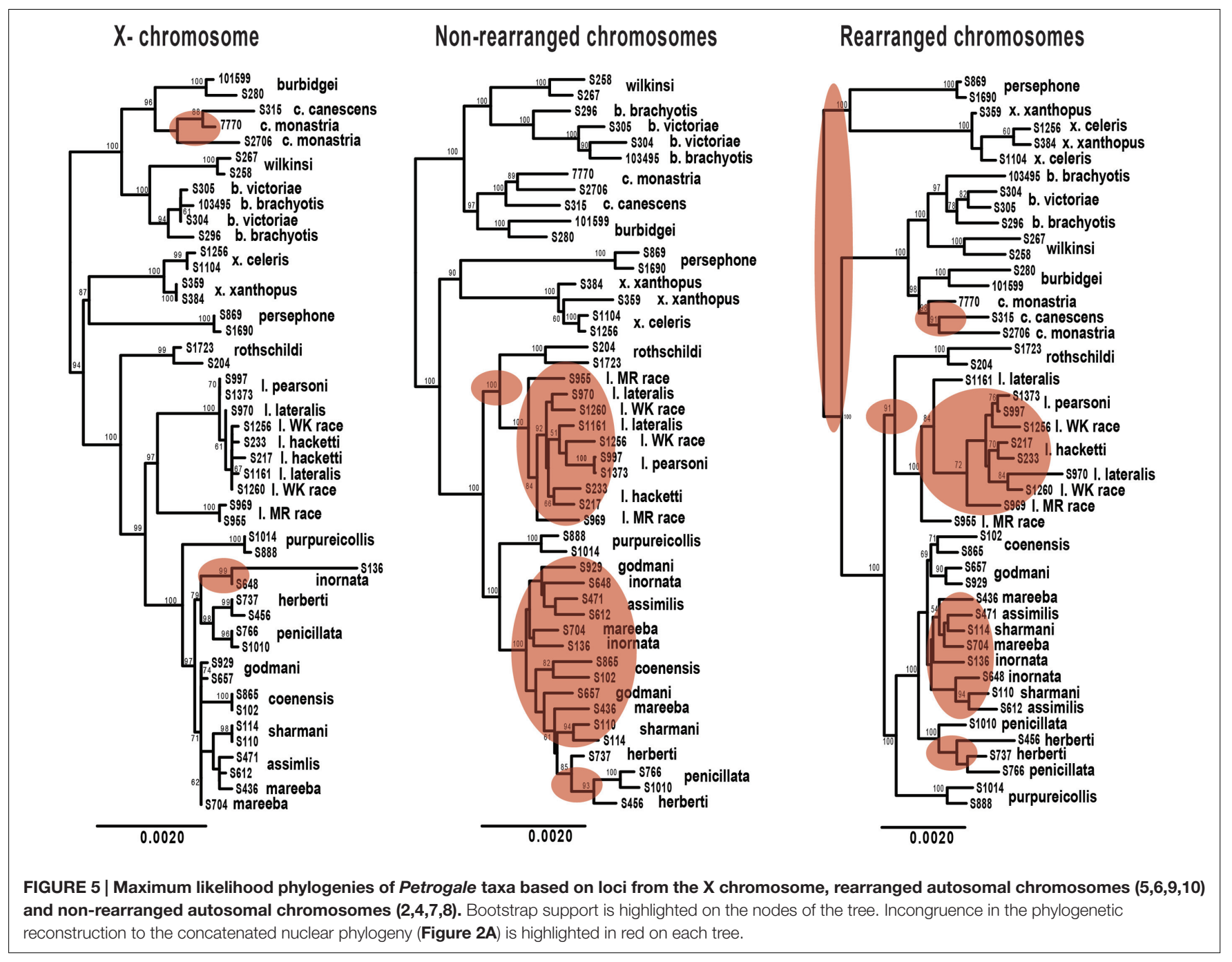

reticulation in the history of Petrogale; in particular, the potential for repeated episodes of introgression in the history of the genus.

We then explored patterns of reticulation among chromosomal groups. We based these analyses on concatenated nuclear loci, effectively ignoring coalescent variance in gene trees. We first used an exploratory statistical approach (NeighborNet in Splits tree - Bryant and Moulton, 2002; Huson and Bryant, 2006, based on average distances). The results suggested reticulation amongst $P$. coenensis and $P$. godmani, between $P$. assimilis, $P$. mareeba and $P$. sharmani, as well as between $P$. lateralis lateralis and $P$. lateralis West Kimberley race (Figure 6). The brachyotis group does not indicate any strong evidence of reticulation between species. The penicillata group results match previous results of microsatellites and mtDNA, which inferred gene flow between these taxa, even those with complex CRs (Potter et al., 2015).

We next used an approach based on the multispecies network coalescent (PhyloNet - Than et al., 2008; Yu et al., 2013, 2014). We find evidence of reticulation for all three chromosomal groups (Figure 6; Supplementary Table 5). Based on our analysis of up to three reticulation events, the results support 2-3 reticulation nodes in the brachyotis group, which suggests historical introgression may explain the discordance between mtDNA and nuclear loci. This included reticulation at nodes of ancestral branches in the brachyotis group. For both the lateralis and penicillata comparisons there was support for a single reticulation node. Within the lateralis group, the reticulation node involved $P$. lateralis West Kimberley race. Reticulation could reflect ILS between $P$. $l$. lateralis and $P . l$. hacketti or introgression with $P$. $l$. lateralis. In the penicillata group, the analyses were less concordant, and the reticulation node included $P$. assimilis and $P$. sharmani for the independent analysis. Both network analyses reflect greater reticulation across all three species and include introgression with $P$. mareeba and $P$. assimilis, as well as ILS amongst the three species. In all three chromosomal group comparisons, reticulation is evident between species with CRs (fusions and centric shifts). Further work is necessary to disentangle the effects of ILS from introgression, which will require further sampling in rearranged vs. nonrearranged regions of chromosomes. 


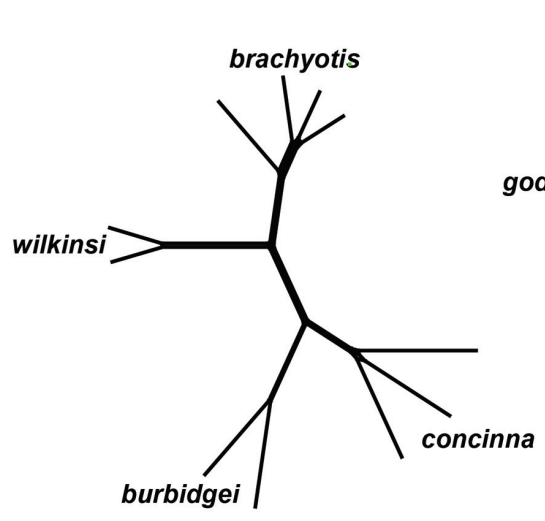

D

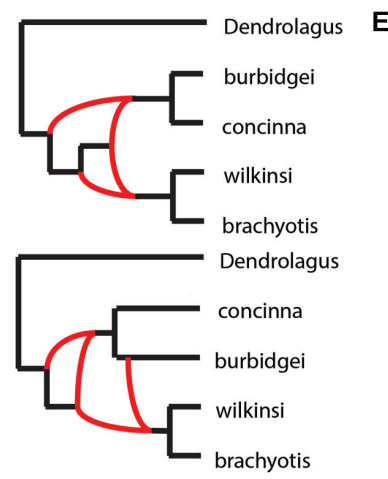

E
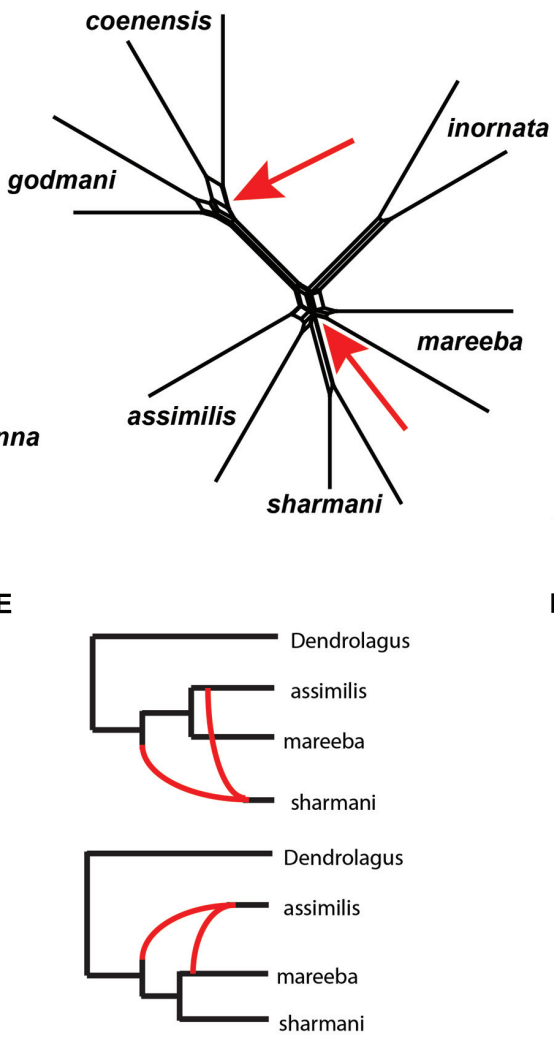

C

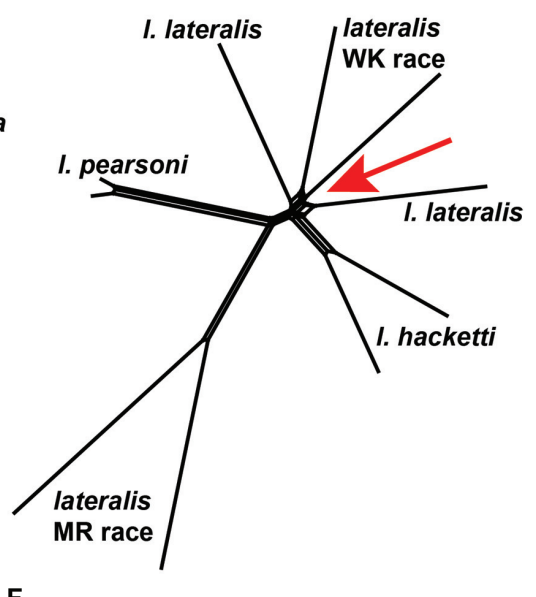

$\mathbf{F}$

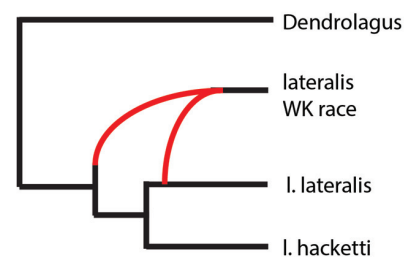

FIGURE 6 | (A-C) A phylogenetic network analysis of the chromosomal groups (A) brachyotis, (B) lateralis, and (C) penicillata estimated using a distance based approach in SplitsTree (Neighbor-Net). The red arrows highlight regions on the network where reticulation is inferred. (D-F) Model based analysis of reticulate evolutionary history based on analysis of 0-3 reticulations. The lowest log likelihood results are shown for each (D) brachyotis, (E) lateralis, and (F) penicillata chromosomal groups using PhyloNet. Analysis was performed on a single individual for each taxon and two replicate analyses, each including one of the two independent samples per taxon. (D) The brachyotis group supported 2-3 reticulations and highlight reticulation involving ancestors in the brachyotis group. (E) The penicillata group analysis include a three species complex (P. assimilis, $P$. mareeba, and $P$. sharmani) and support a single reticulation model but alternate topologies and individuals involved in reticulation based on the individuals used in the analysis. (F) The lateralis group analyses included three taxa (P. I. lateralis, P. I. hacketti and $P$. I. West Kimberley race). The results were congruent in identifying a single reticulation model, which involved the $P$. lateralis West Kimberley race.

Understanding the genome, the physical position of loci and how they interact is crucial in interpreting the evolutionary history of organisms. Our results highlight that if certain loci taken alone without any context of chromosome structure can yield completely different results and a misunderstanding of the mechanisms involved in reproductive isolation. We are still in the early stages of understanding the physical location of loci in this non-model system and as further work allows mapping of loci to chromosomes and regions of rearrangements, we will be better able to test for recombination suppression and reduced gene flow in these regions compared to the non-rearranged chromosomes. With the addition of X chromosome loci, we may be able to further understand the genetic variation on the $\mathrm{X}$ which itself has a high rate of intrachromosomal rearrangement in this system. The combined effects of faster $\mathrm{X}$ divergence and reduced recombination may affect speciation in this genus. Below, we outline the necessary steps to progress this non-model system a framework we believe useful for any non-model speciation research.

\section{PROSPECTUS}

The case study above, for a fascinating yet "non-model" system, indicates both the promise and the challenges of arriving at a holistic understanding of how CRs affect divergence and adaptation. Hybrid infertility and recombination suppression (adaptive) models have largely been treated as exclusive, but in systems with complex rearrangements, both could well be in play (Faria and Navarro, 2010; Garagna et al., 2014). Further, such hypotheses should not be treated as exclusive of accumulation of genic incompatibilities, such as large X-effects (Presgraves, 2008), effects of recessive X-linked incompatibility alleles on sterility of the heterogametic sex (Haldane's rule; Haldane, 1922; Turelli, 1998; Presgraves, 2008, 2010) or cytonuclear incompatibilities (Turelli and Moyle, 2007). In addition to new evidence across diverse systems, we need further development of theory that incorporates these co-occurring processes (Feder and Nosil, 2009; Faria and Navarro, 2010). We should also consider extended models with meiotic drive, genomic conflict 


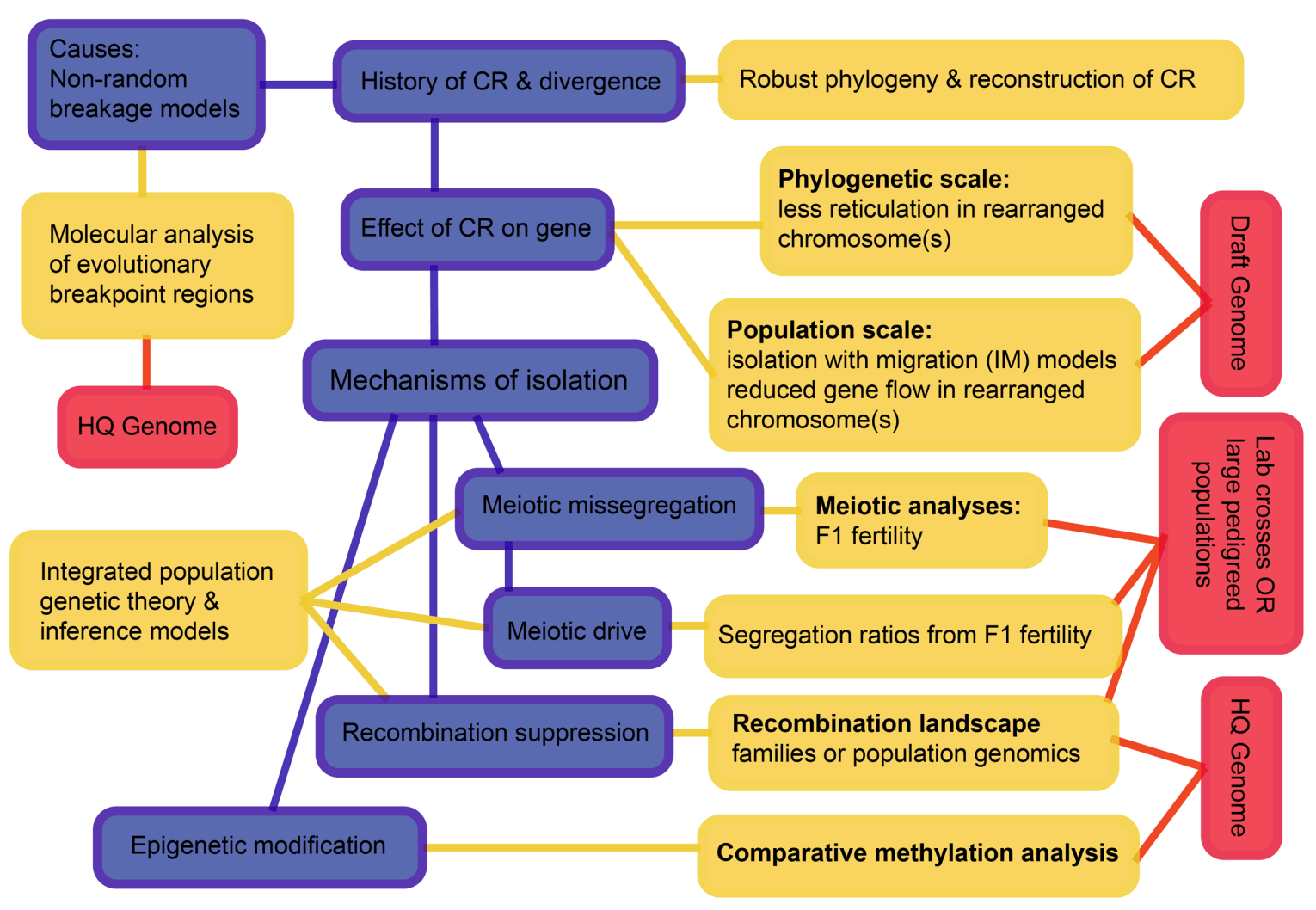

FIGURE 7|A schematic overview of an integrative approach to increase understanding how chromosomal rearrangements create divergence and speciation. The hierarchy outlined progresses from simple to complex and may not be feasible for all non-model systems, but outlines the ultimate goals. Blue boxes highlight the processes, yellow boxes highlight the analyses and red boxes highlight the data needed to achieve a holistic understanding of chromosomal speciation. $\mathrm{CR}$, chromosome rearrangement; $\mathrm{HQ}$, high quality.

and disruption of epigenetic programming (Brown and O’Neill, 2010).

Considering all these interacting processes, we suggest a hierarchy of questions and associated requirements that progress from simple to challenging (Figure 7). The first question is the history of speciation and CRs, as we have now begun to resolve for the rock-wallabies. We move on to testing the effects of CRs on the suppression of gene flow, and then to testing mechanisms that may have suppressed gene flow. The scale and diversity of data needed expands as we move from pattern to process. Of particular note is the need to develop new theory and inference methods that can distinguish the different processes by integrating genomic data, recombination landscapes, meiotic irregularities, segregation patterns, and epigenetics. Such methods involve complicated parameter estimation and may need to rely on approaches such as approximate Bayesian computation (ABC) to compare competing models (see Beaumont, 2010). Those models, in turn, will likely employ multispecies coalescence that includes speciation and demographic history, as well as the evolution of CRs (e.g., coalescent models for CRs - Guerrero et al., 2012a,b; Ayala et al., 2013; Peischl et al., 2013). The quality of genome assemblies needed increases as we move from pattern to process. This is crucial to remove errors that can influence inference of rearrangements as well as recombination rate changes.
In the following, we explore three key issues that have emerged: (i) what do we know of differential origins of new (or recurrent) CRs; (ii) how do CRs interact with the epigenetic programming of genes and chromosome segments; and (iii) what new theory and inference methods do we need to exploit comparative genomic data in the context of individual and combined effects of CRs.

\section{Origins of CRs}

Recent reviews highlight that the breakpoints of CRs are associated with repetitive elements, and are influenced by functional constrains and meiotic recombination (Farré et al., 2015). These features have been discovered from whole genome comparisons of distantly and closely related species. Repetitive sequences, such as segmental duplications and transposable elements, appear to provide the substrates for non-allelic homologous recombination (Bailey et al., 2004; Cordaux and Batzer, 2009), resulting in CRs such as inversions. These breakpoint regions are also common in gene-dense regions of the genome, with the breaks occurring predominantly in intergenic regions where they are less likely to silence a gene (Lemaitre et al., 2009). Breakpoint regions are enriched with genes involved in adaptive processes, such as immune response genes, and CRs causing changes to expression of these genes 
or otherwise rendering a gene non-functional could provide a selective advantage to result in the fixation of this rearrangement (Larkin et al., 2009; Ullastres et al., 2014). Furthermore, generich regions have been shown to be more actively transcribed, possessing epigenetic characteristics of open, and therefore accessible, chromatin (Lemaitre et al., 2009; Capilla et al., 2016). This makes sense in light of the observation that meiotic double strand breaks required for CRs typically occur in transcriptionally active, open chromatin regions of the genome (Smagulova et al., 2011).

Rearrangements involving centromeres are common in many systems, including Petrogale. Similar to the breakpoint regions described above, centromeres contain highly repetitive sequences. Robertsonian fusions may be formed from illegitimate recombination occurring among these highly repetitive sequences (Slijepcevic, 1998; Garagna et al., 2001; RuizHerrera et al., 2006). Nuclear architecture also appears to play a role in the formation of Robertsonian fusions. In mice, the pericentric regions of telocentric chromosomes converge during the leptotene stage of prophase I in meiosis, placing pericentromeric regions of different chromosomes in close proximity (Garagna et al., 2014). Prophase I is also the time when DNA is damaged and the cell is repairing the doublestranded breaks by homologous recombination for synapsis of homologous chromosomes (Neale and Keeney, 2006). The combination of these two factors lends this phase of meiosis to being a time of potential CR (Garagna et al., 2014). More generally, the location of chromosomes within the nucleus should be considered when studying CRs as it could help to understand why some chromosomes or chromosome arms more commonly involved in CRs than other chromosomes (Wesche and Robinson, 2012).

In some cases, the CR involving the centromere is a centric shift. This could occur via a pericentric inversion. Alternatively, neocentromeres may be established from epigenetic changes to repetitive sequences located elsewhere on the chromosome and old centromeres decommissioned (O’Neill et al., 2004). Also, a three-break rearrangement that allows the centromere to be excised and then reinserted in a different position further along the chromosome could occur (Eldridge et al., 1988). O'Neill et al. (2004) suggested that heterochromatin stabilizes centromere position and its absence opens the way for neocentromerization. Although cause and consequence remain difficult to distinguish, and further exploration of this hypothesis in Petrogale would be of value.

The characterization of breakpoint features and the role of centromeres in CRs has made it evident that sequence content, an open chromatin conformation and chromosome territories within the nucleus in the germline are all important for understanding the origin of CRs and should be considered together (i.e., the "Integrative Breakage Model," Farré et al., 2015). Detailed studies of epigenomic features and chromatin conformation are possible for model species like the mouse (Capilla et al., 2016), testing the Integrative Breakage Model may be more challenging at present for non-model species as a high-quality reference genome is essential for interpreting epigenomic data. However, advances in sequencing technology and the corresponding genome assembly pipelines (e.g., Putnam et al., 2016), make this achievable for non-model species.

\section{Interaction of CRs with Epigenetic Programming}

Epigenetic variation has recently been recognized to cause genetic incompatibilities that can lead to reproductive isolation (Brown and O'Neill, 2010; Durand et al., 2012). The only known "speciation gene" in mammals is $\operatorname{Prdm} 9$ in mice (Mihola et al., 2009). It encodes for the meiotic specific-protein responsible for marking the location of recombination hotspots (Grey et al., 2011). Recombination is essential recognition of chromosome homologues during prophase I of meiosis and its disruption results in sterile male hybrids. An interaction between the autosomal Prdm9 and the X-linked Meirl gene contributes to reproductive isolation of Mus musculus musculus and Mus m. domesticus subspecies (Balcova et al., 2016). Robertsonian fusions alter the epigenetic marks of $\mathrm{H} 3 \mathrm{~K} 9 \mathrm{me} 3$ and $\gamma \mathrm{H} 2 \mathrm{AX}$ (Capilla et al., 2014). The accumulation of $\gamma \mathrm{H} 2 \mathrm{AX}$ is associated with the MSUC mechanism, which is similar to meiotic sex chromosome inactivation (MSCI) for silencing the unsynapsed $\mathrm{X}$ and $\mathrm{Y}$ in males. These mechanisms involve a suite of epigenetic modifications to achieve transcriptional silencing of the sex chromosomes (MSCI) or unsynapsed region (MSUC) (reviewed in Turner, 2007). When CRs reduce recombination, MSUC may therefore silence genes critical to meiosis (Shiu et al., 2001) and cause infertility (Garagna et al., 2014).

The frequent involvement of centromeres in CRs makes it interesting to consider the role of these important structures in speciation. Sequences at centromeres rapidly evolve, differing markedly between closely related species. Chromatin-binding proteins, such as various histone proteins, are important for the normal function of a centromere during meiosis and mitosis. Reproductive isolation could result from incompatibilities in these proteins, with chromatin-binding proteins from one species failing to recognize the repeat sequence of the other (Sawamura et al., 2012). Centromere incompatibilities could then lead to centromere-drive where there is an imbalance in centromere strength during meiosis, contributing to post-zygotic isolation (Henikoff et al., 2001; Malik and Henikoff, 2003).

\section{Population Genetics - Theory and Inference}

Substantial progress has been made toward understanding speciation using sequence data. Faria and Navarro (2010) develop a framework based on the models of Navarro and Barton (2003) and Kirkpatrick and Barton (2006) to study how CRs contribute to speciation and how they first become fixed in different populations. This links population genetics theory to speciation and encompasses a model of how CRs have become fixed outside of previous models based on drift (Walsh, 1982; Lande, 1985; Spirito, 1998), selective advantages (Nei et al., 1967), meiotic drive (Nei et al., 1967), or epistatic interactions (Charlesworth, 1974). 
There is the need for development of models that incorporate synergistic effects of genic and chromosomal variation, as well as the effects of drift and selection. Such models might provide opportunities to evaluate when a single process can explain observed patterns of variation in a dataset, and when multiple interacting processes need to be invoked. However, the reality is that genic and chromosomal divergences occur in parallel, CRs potentially have multiple effects, and that such models will only be capable of distinguishing among hypothesized processes in the simplest of systems. Here comparative genomic datasets, in particular lineages with a history of recent CRs, might offer unique opportunities. With such data, it is possible to test predictions of molecular evolution and biogeography, but empirical data can produce similar signatures under different scenarios (Noor and Bennett, 2009). One possible way forward is to exploit the different types of evidence (Figure 7) to set up competing/complementary models of single and joint effects that could then be evaluated using comparative sequence data.

In systems with multiple CRs, like the Petrogale system described here, we can view each $\mathrm{CR}$ as a semi-independent evolutionary replicate, providing opportunities to examine how different independent CRs, fixing in populations at different times, relate to genic divergence. This in turn can inform our understanding of processes. For instance, evidence of synchrony in fixation of different rearrangements may provide evidence of meiotic drive (e.g., Pardo-Manuel de Villena and Sapienza, 2001). Under meiotic drive hypotheses, we expect rearrangements will be of similar ages. If, however, CRs generate beneficial fitness effects (spread by positive selection), we do not expect fixation to occur at similar times. With combined cytogenetic understanding, this allows us to fit models to different regions along each chromosome to capture their unique evolutionary histories. If rearrangements are important to divergence, we expect the times at which they are established to coincide with speciation events. Using coalescent models to date speciation events and then mapping rearrangements on these phylogenies will help elucidate which CRs could have been involved in speciation (also previously suggested by Faria and Navarro, 2010). The key here will be finding systems where CRs are relatively recent, to distinguish between genic divergence post speciation vs. mutations causing reproductive isolation in relation to genomic architecture.

\section{CONCLUSION}

Integration of cytogenetic, genomic, and epigenetic data using a holistic approach will be crucial to improving our understanding of how genomic architecture influences and potentially drives reproductive isolation amongst organisms. The non-model system highlighted here has value for many reasons aside from its recent origin and chromosomal diversity. These include: the effect of reversed recombination rate between the sexes in marsupials relative to most other eutherians (males > females), $\mathrm{X}$ and $\mathrm{Y}$ chromosomes do not pair during meiosis (they lack the pseudoautosomal region), and epigenetic mechanisms vary significantly from eutherians. This one non-model system illustrates how biological variation can provide valuable contrasts to model systems. The growth of genomic and computational technology is opening new vistas on fundamental questions about how genomic architecture influences evolution.

\section{DATA ACCESSIBILITY}

Raw sequencing reads associated with this study are available at NCBI Sequence Read Archive (http://www.ncbi.nlm.nih.gov/ sra; BioProject PRJNA360868; BioSamples SAMN06233288SAMN06233338). A Dryad Repository (http://dx.doi.org/10. 5061/dryad.mm856) contains code that was used in data analysis and Sequence Read Archive accession details.

\section{ETHICS STATEMENT}

This study did not use live animals and therefore does not require animal ethics approval. Samples used were tissues from the Australian Museum collection. Animal research at the Australian Museum and in Australia is governed by the "Australian code for the care and use of animals for scientific purposes." The Code only requires a research project to be approved by an ethics committee if the research involves live animals.

\section{AUTHOR CONTRIBUTIONS}

SP had substantial contribution to the conception, acquisition, design, analysis and interpretation of the work, drafting the work, final approval of the version to be published and agreement to be accountable for all aspects of the work. JB had substantial contribution to the conception, design, analysis and interpretation of the work, drafting the work, final approval of the version to be published and agreement to be accountable for all aspects of the work. MB had substantial contribution to the analysis of the work, drafting the work, final approval of the version to be published and agreement to be accountable for all aspects of the work. JD had substantial contribution to the conception, acquisition and design of the work, drafting the work, final approval of the version to be published and agreement to be accountable for all aspects of the work. MK had substantial contribution to the conception of the work, drafting the work, final approval of the version to be published and agreement to be accountable for all aspects of the work. ME and CM had substantial contribution to the conception, acquisition, design and interpretation of the work, drafting the work, final approval of the version to be published and agreement to be accountable for all aspects of the work.

\section{FUNDING}

This research was supported by an Australian Research Council Discovery Grant (DP160100187) as well as and ARC Laureate Fellowship awarded to CM (ARC FL110100104). 


\section{ACKNOWLEDGMENTS}

We would like to thank the Australian Museum and South Australian Museum for samples. In addition, we would like to thank all the individuals that contributed tissues that were used in this study. We would like to thank Rachel O'Neill for access to the tammar wallaby genome. We thank Maxine Piggott for assistance with laboratory work. We would also like to thank members of the Moritz and Kirkpatrick labs for ongoing discussions relating to this study, in particular Josh Penalba and Ana Silva

\section{REFERENCES}

Ayala, D., Guerrero, R. F., and Kirkpatrick, M. (2013). Reproductive isolation and local adaptation quantified for a chromosome inversion in a malaria mosquito. Evolution 67, 946-958. doi: 10.1111/j.1558-5646.2012.01836.x

Bailey, J. A., Baertsch, R., Kent, W. J., Haussler, D., and Eichler, E. E. (2004). Hotspots of mammalian chromosomal evolution. Genome Biol. 5:R23. doi: 10.1186/gb-2004-5-4-r23

Baird, A. B., Hillis, D. M., Patton, J. C., and Bickham, J. W. (2009). Speciation by monobrachial centric fusions: a test of the model using nuclear DNA sequences from the bat genus Rhogeessa. Mol. Phylogenet. Evol. 50, 256-267. doi: 10.1016/ j.ympev.2008.11.001

Baker, R. J., and Bickham, J. W. (1986). Speciation by monobrachial centric fusions. Proc. Natl. Acad. Sci. U.S.A. 83, 8245-8248. doi: 10.1073/pnas.83.21.8245

Balcova, M., Faltusova, B., Gergelits, V., Bhattacharyya, T., Mihola, O., Trachtulec, Z., et al. (2016). Hybrid sterility locus on chromosome X controls meiotic recombination rate in mouse. PLoS Genet. 12:e1005906. doi: 10.1371/ journal.pgen.1005906

Basset, P., Yannic, G., Brünner, H., and Hausser, J. (2006). Restricted gene flow at specific parts of the shrew genome in chromosomal hybrid zones. Evolution 60 , 1718-1730. doi: 10.1554/06-181.1

Bateson, W. (1909). "Heredity and variation in modern lights," in Darwin and Modern Science, ed. A. C. Seward (Cambridge: Cambridge University Press), 85-101.

Beaumont, M. A. (2010). Approximate Bayesian computation in evolution and ecology. Annu. Rev. Ecol. Evol. Syst. 41, 379-406. doi: 10.1146/annurev-ecolsys102209-144621

Bee, C. A., and Close, R. L. (1993). Mitochondrial DNA analysis of introgression between adjacent taxa of rock-wallabies, Petrogale species (Marsupialia: Macropodidae). Genet. Res. 61, 21-37. doi: 10.1017/S0016672300031074

Bergero, R., and Charlesworth, D. (2009). The evolution of restricted recombination in sex chromosomes. Trends Ecol. Evol. 24, 94-102. doi: 10.1016/j.tree.2008.09.010

Borodin, P. M., Ladygina, T. Y., Rodionova, M. I., Zhelezova, A. I., Zykovich, A. S., and Axenovich, T. I. (2005). Genetic control of chromosome synapsis in mice heterozygous for a paracentric inversion. Russ. J. Genet. 41, 602-607. doi: 10.1007/s11177-005-0133-6

Briscoe, D. A., Calaby, J. M., Close, R. L., Maynes, G. M., Murtagh, C. E., and Sharman, G. B. (1982). "Isolation, introgression and genetic variation in rock wallabies," in Species at Risk: Research in Australia, eds R. H. Groves and W. D. L. Ryde (Canberra, ACT: Australian Academy of Science), 73-87.

Brown, J. D., and O'Neill, R. J. (2010). Chromosomes, conflict, and epigenetics: chromosomal speciation revisited. Annu. Rev. Genomics Hum. Genet. 11, 291316. doi: 10.1146/annurev-genom-082509-141554

Bryant, D., and Moulton, V. (2002). "NeighborNet: an agglomerative method for the construction of planar phylogenetic networks," in International Workshop on Algorithms in Bioinformatics, R. Guigó and D. Gusfield (Heidelberg: Springer), 375-391.

Bulazel, K. V., Ferreri, G. C., Eldridge, M. D. B., and O’Neill, R. J. (2007). Species-specific shifts in centromere sequence composition are coincident with breakpoint reuse in karyotypically divergent lineages. Genome Biol. 8:R170. doi: $10.1186 / g b-2007-8-8-r 170$ for advice on analyses. We thank Ke Bi and Sonal Singhal for providing scripts and for discussions. This work used the ACRF Biomolecular Resource Facility at ANU.

\section{SUPPLEMENTARY MATERIAL}

The Supplementary Material for this article can be found online at: http://journal.frontiersin.org/article/10.3389/fgene. 2017.00010/full\#supplementary-material

Bush, G. L., Case, S. M., Wilson, A. C., and Patton, J. L. (1977). Rapid speciation and chromosome evolution in mammals. Proc. Natl. Acad. Sci. U.S.A. 74, 3942-3946. doi: 10.1073/pnas.74.9.3942

Campeau-Péloquin, A., Kirsch, J. A., Eldridge, M. D., and Lapointe, F. J. (2001). Phylogeny of the rock-wallabies, Petrogale (Marsupialia: Macropodidae) based on DNA/DNA hybridisation. Aust. J. Zool. 49, 463-486. doi: 10.1071/ZO01034

Capilla, L., Medarde, N., Alemany-Schmidt, A., Oliver-Bonet, M., Ventura, J., and Ruiz-Herrera, A. (2014). Genetic recombination variation in wild Robertsonian mice: on the role of chromosomal fusions and Prdm9 allelic background. Proc. R. Soc. Lond. 281:20140297. doi: 10.1098/rspb.2014.0297

Capilla, L., Sánchez-Guillén, R. A., Farré, M., Paytuví-Gallart, A., Malinverni, R., Ventura, J., et al. (2016). Mammalian comparative genomics reveals genetic and epigenetic features associated with genome reshuffling in Rodentia. Genome Biol. Evol. doi: 10.1093/gbe/evw276

Carbone, L., Harris, R. A., Gnerre, S., Veeramah, K. R., Lorente-Galdos, B., Huddleston, J., et al. (2014). Gibbon genome and the fast karyotype evolution of small apes. Nature 513, 195-201. doi: 10.1038/nature13679

Charlesworth, B. (1974). Inversion polymorphism in a two-locus genetic system. Genetical Res. 23, 259-280. doi: 10.1017/S0016672300014919

Charlesworth, B., Coyne, J. A., and Barton, N. H. (1987). The relative rates of evolution of sex chromosomes and autosomes. Am. Nat. 130, 113-146. doi: $10.1086 / 284701$

Chmátal, L., Gabriel, S. I., Mitsainas, G. P., Martínez-Vargas, J., Ventura, J., Searle, J. B., et al. (2014). Centromere strength provides the cell biological basis for meiotic drive and karyotype evolution in mice. Curr. Biol. 24, 2295-2300. doi: 10.1016/j.cub.2014.08.017

Close, R. L., Bell, J. N., Dollin, A. E., and Harding, H. R. (1996). Spermatogenesis and synaptonemal complexes of hybrid Petrogale (Marsupialia). J. Hered. 87, 96-107. doi: 10.1093/oxfordjournals.jhered.a0229829

Cordaux, R., and Batzer, M. A. (2009). The impact of retrotransposons on human genome evolution. Nat. Rev. Genet. 10, 691-703. doi: 10.1038/nrg2640

Coyne, J. A., Barton, N. H., and Turelli, M. (2000). Is Wright's shifting balance process important in evolution? Evolution 54, 306-317. doi: 10.1111/j.00143820.2000.tb00033.x

Coyne, J. A., and Orr, H. A. (2004). Speciation. Sunderland, MA: Sinauer Associates. Crawford, J. E., Riehle, M. M., Guelbeogo, W. M., Gneme, A., Sagnon, N. F., Vernick, K. D., et al. (2015). Reticulate speciation and barriers to introgression in the Anopheles gambiae species complex. Genome Biol. Evol. 7, 3116-3131. doi: $10.1093 /$ gbe/evv203

Cui, R., Schumer, M., Kruesi, K., Walter, R., Andolfatto, P., and Rosenthal, G. G. (2013). Phylogenomics reveals extensive reticulate evolution in Xiphophorus fishes. Evolution 67, 2166-2179. doi: 10.1111/evo.12099

Darlington, C. D. (1958). The Evolution of Genetic Systems, 2nd Edn. New York, NY: Basic Books Inc.

Dobigny, G., Britton-Davidian, J., and Robinson, T. J. (2017). Chromosomal polymorphism in mammals: an evolutionary perspective. Biol. Rev. Camb. Philos. Soc. 92, 1-21. doi: 10.1111/brv.12213

Dobzhansky, T. (1936). Studies on hybrid sterility. II. Localization of sterility factors in Drosophila pseudoobscura hybrids. Genetics 21, 113-135.

Dobzhansky, T. (1950). Genetics of natural populations XIX Origin of heterosis through natural selection in populations of Drosophila pseudoobscura. Genetics $35,288-302$. 
Durand, E. Y., Patterson, N., Reich, D., and Slatkin, M. (2011). Testing for ancient admixture between closely related populations. Mol. Biol. Evol. 28, 2239-2252. doi: 10.1093/molbev/msr048

Durand, S., Bouché, N., Strand, E. P., Loudet, O., and Camilleri, C. (2012). Rapid establishment of genetic incompatibility through natural epigenetic variation. Curr. Biol. 22, 326-331. doi: 10.1016/j.cub.2011.12.054

Edwards, S. V., Potter, S., Schmitt, C. J., Bragg, J. G., and Moritz, C. (2016). Reticulation, divergence, and the phylogeography-phylogenetics continuum. Proc. Natl. Acad. Sci. U.S.A. 113, 8025-8032. doi: 10.1073/pnas.1601066113

Eldridge, M. D. B. (2008). "Rock-wallabies: Petrogale," in The Mammals of Australia, 3rd Edn, ed. S. Van Dyck and R. Strahan (Chatswood, NSW: New Holland Publishers Pty Ltd), 361.

Eldridge, M. D. B., and Close, R. L. (1992). Taxonomy of rock wallabies, Petrogale (Marsupialia, Macropodidae). I. A revision of the eastern Petrogale with the description of 3 new species. Aust. J. Zool. 40, 605-625. doi: 10.1071/ZO9920605

Eldridge, M. D. B., and Close, R. L. (1993). Radiation of chromosome shuffles. Curr. Opin. Genet. Dev. 3, 915-922. doi: 10.1016/0959-437X(93)90014-G8

Eldridge, M. D. B., and Close, R. L. (1997). Chromosomes and evolution in rockwallabies, Petrogale (Marsupialia: Macropodidae). Aust. Mammal. 19, 123-136.

Eldridge, M. D. B., Close, R. L., and Johnston, P. G. (1990). Chromosomal rearrangements in rock wallabies, Petrogale (Marsupialia: Macropodidae). III. G-banding analysis of the Petrogale inornata and P. penicillata. Genome 33, 798-802. doi: 10.1139/g90-120

Eldridge, M. D. B., Close, R. L., and Johnston, P. G. (1991). Chromosomal rearrangements in rock wallabies, Petrogale (Marsupialia: Macropodidae). IV. G-banding analysis of the Petrogale lateralis complex. Aust. J. Zool. 39, 621-627. doi: $10.1071 /$ ZO9910629

Eldridge, M. D. B., Dollin, A. E., Johnston, P. G., Close, R. L., and Murray, J. D. (1988). Chromosomal rearrangements in rock wallabies, Petrogale (Marsupialia, Macropodidae). I. The P. assimilis species complex. G-banding and synaptonemal complex analysis. Cytogenet. Cell Genet. 48, 228-232. doi: $10.1159 / 000132634$

Eldridge, M. D. B., and Johnston, P. G. (1993). Chromosomal rearrangements in rock wallabies, Petrogale (Marsupialia: Macropodidae). VIII. An investigation of the non-random nature of karyotypic change. Genome 36, 524-534. doi: 10.1139/g93-072

Eldridge, M. D. B., Johnston, P. G., and Close, R. L. (1992a). Chromosomal rearrangements in rock wallabies, Petrogale (Marsupialia: Macropodidae). VI. Determination of the plesiomorphic karyotype: G-Banding comparison of Thylogale with Petrogale persephone, P. xanthopus, and P. l. lateralis. Cytogenet. Cell Genet. 61, 29-33.

Eldridge, M. D. B., Johnston, P. G., Close, R. L., and Lowry, P. S. (1989). Chromosomal rearrangements in rock wallabies, Petrogale (Marsupialia: Macropodidae). II. G-banding analysis of Petrogale godmani. Genome 32, 935-940. doi: 10.1139/g89-5348

Eldridge, M. D. B., Johnston, P. G., and Lowry, P. S. (1992b). Chromosomal rearrangements in rock wallabies, Petrogale (Marsupialia: Macropodidae). VII. G-banding analysis of $P$. brachyotis and P. concinna: species with dramatically altered karyotypes. Cytogenet. Cell Genet. 61, 34-39. doi: 10.1159/0001333649

Faria, R., and Navarro, A. (2010). Chromosomal speciation revisited: rearranging theory with pieces of evidence. Trends Ecol. Evol. 25, 660-669. doi: 10.1016/j. tree.2010.07.008

Farré, M., Robinson, T. J., and Ruiz-Herrera, A. (2015). An integrative breakage model of genome architecture, reshuffling and evolution. Bioessays 37, 479-488. doi: 10.1002/bies.201400174

Feder, J. L., and Nosil, P. (2009). Chromosomal inversions and species differences: when are genes affecting adaptive divergence and reproductive isolation expected to reside within inversions? Evolution 63, 3061-3075. doi: 10.1111/j. 1558-5646.2009.00786.x

Fedyk, S., and Chętnicki, W. (2007). Preferential segregation of metacentric chromosomes in simple Robertsonian heterozygotes of Sorex araneus. Heredity 99, 545-552. doi: 10.1038/sj.hdy.6801036

Fontaine, M. C., Pease, J. B., Steele, A., Waterhouse, R. M., Neafsey, D. E., Sharakhov, I. V., et al. (2015). Extensive introgression in a malaria vector species complex revealed by phylogenomics. Science 347:1258524. doi: 10.1126/science. 1258524

Förster, D. W., Jones, E. P., Jóhannesdóttir, F., Gabriel, S. I., Giménez, M. D., Panithanarak, T., et al. (2016). Genetic differentiation within and away from the chromosomal rearrangements characterising hybridising chromosomal races of the western house mouse (Mus musculus domesticus). Chromosome Res. 24, 271-280. doi: 10.1007/s10577-016-9520-1

Franchini, P., Colangelo, P., Solano, E., Capanna, E., Verheyen, E., and Castiglia, R. (2010). Reduced gene flow at pericentromeric loci in a hybrid zone involving chromosomal races of the house mouse Mus musculus domesticus. Evolution 64, 2020-2032. doi: 10.1111/j.1558-5646.2010.00964.x

Futuyma, D. J., and Mayer, G. C. (1980). Non-allopatric speciation in animals. Syst. Zool. 29, 254-271. doi: 10.2307/2412661

Garagna, S., Marziliano, N., Zuccotti, M., Searle, J. B., Capanna, E., and Redi, C. A. (2001). Pericentromeric organization at the fusion point of mouse Robertsonian translocation chromosomes. Proc. Natl. Acad. Sci. U.S.A. 98, 171-175. doi: 10.1073/pnas.98.1.171

Garagna, S., Page, J., Fernandez-Donoso, R., Zuccotti, M., and Searle, J. B. (2014). The Robertsonian phenomenon in the house mouse: mutation, meiosis and speciation. Chromosoma 123, 529-544. doi: 10.1007/s00412-014-0 477-6

Giménez, M. D., White, T. A., Haufe, H. C., Panithanarak, C., and Searle, J. B. (2013). Understanding the basis of diminished gene flow between hybridizing chromosome races of the house mouse. Evolution 67, 1446-1462. doi: 10.1111/ evo. 12054

Grant, V. (1964). The architecture of the germ plasm. Soil Sci. 98:212. doi: 10.1097/ 00010694-196409000-00032

Graves, J. A. M., and Renfree, M. B. (2013). Marsupials in the age of genomics. Annu. Rev. Genomics Hum. Genet. 14, 393-420. doi: 10.1146/annurev-genom091212-153452

Green, R. E., Krause, J., Briggs, A. W., Maricic, T., Stenzel, U., Kircher, M., et al. (2010). A draft sequence of the Neandertal genome. Science 328, 710-722. doi: $10.1126 /$ science. 1188021

Grey, C., Barthès, P., Chauveau-Le Friec, G., Langa, F., Baudat, F., and De Massy, B. (2011). Mouse PRDM9 DNA-binding specificity determines sites of histone $\mathrm{H} 3$ lysine 4 trimethylation for initiation of meiotic recombination. PLoS Biol. 9:e1001176. doi: 10.1371/journal.pbio.1001176

Guerrero, R. F., and Kirkpatrick, M. (2014). Local adaptation and the evolution of chromosome fusions. Evolution 68, 2747-2756. doi: 10.1111/evo.12481

Guerrero, R. F., Kirkpatrick, M., and Perrin, N. (2012a). Cryptic recombination in the ever-young sex chromosomes of Hylid frogs. J. Evol. Biol. 25, 1947-1954. doi: 10.1111/j.1420-9101.2012.02591.x

Guerrero, R. F., Rousset, F., and Kirkpatrick, M. (2012b). Coalescent patterns for chromosomal inversions in divergent populations. Philos. Trans. R. Soc. Lond. B Biol. Sci. 367, 430-438. doi: 10.1098/rstb.2011.0246

Guichaoua, M. R., Delafontaine, D., Taurelle, R., Taillemite, J. L., Morazzani, M. R., and Luciani, J. M. (1986). Loop formation and synaptic adjustment in a human male heterozygous for two pericentric inversions. Chromosoma 93, 313-320. doi: $10.1007 / \mathrm{BF} 003275895$

Haldane, J. B. S. (1922). Sex ratio and unisexual sterility in hybrid animals. J. Genet. 12, 101-109. doi: 10.1007/BF02983075

Harewood, L., and Fraser, P. (2014). The impact of chromosomal rearrangements on regulation of gene expression. Hum. Mol. Gen. 23, R76-R82. doi: 10.1093/ hmg/ddu 278

Hayman, D. L. (1990). Marsupial cytogenetics. Aust. J. Zool. 37, 331-349. doi: 10.1071/ZO9890331

Hazlitt, S. L., Goldizen, A. W., and Eldridge, M. D. B. (2006). Significant patterns of population genetic structure and limited gene flow in a threatened macropodid marsupial despite continuous habitat in southeast Queensland, Australia. Conserv. Genet. 7, 675-689. doi: 10.1007/s10592-005-9101-x

Henikoff, S., Ahmad, K., and Malik, H. S. (2001). The centromere paradox: stable inheritance with rapidly evolving DNA. Science 293, 1098-1102. doi: 10.1126/ science. 1062939

Henzel, J. V., Nabeshima, K., Schvarzstein, M., Turner, B. E., Villeneuve, A. M., and Hillers, K. J. (2011). An asymmetric chromosome pair undergoes synaptic adjustment and crossover redistribution during Caenorhabditis elegans meiosis: implications for sex chromosome evolution. Genetics 187, 685-699. doi: 10. 1534/genetics.110.124958

Hoffmann, A. A., and Rieseberg, L. H. (2008). Revisiting the impact of inversions in evolution: from population genetic markers to drivers of adaptive shifts and speciation? Annu. Rev. Ecol. Evol. Syst. 39, 21-42. doi: 10.1146/annurev.ecolsys. 39.110707.173532 
Hooper, D. M., and Price, T. (2015). Rates of karyotypic evolution in Estrildid finches differ between island and continental clades. Evolution 69, 890-903. doi: 10.1111/evo.12633

Horn, A., Basset, P., Yannic, G., Banaszek, A., Borodin, P. M., Bulatova, N. S., et al. (2012). Chromosomal incompatibilities do not seem to affect the gene flow in hybrid zones between karyotypic races of the common shrew (Sorex araneus). Evolution 66, 882-889. doi: 10.1111/j.1558-5646.2011.01478.x

Huson, D. H., and Bryant, D. (2006). Application of phylogenetic networks in evolutionary studies. Mol. Biol. Evol. 23, 254-267. doi: 10.1093/molbev/msj030

James, S. H. (1982). "Coadaptation of the genetic system and the evolution of isolation among populations of Western Australian native plants," in Mechanisms of Speciation, ed. C. Barigozzi (New York, NY: Alan R. Liss Inc.), 461-470.

Johannisson, R., and Winking, H. (1994). Synaptonemal complexes of chains and rings in mice heterozygous for multiple Robertsonian translocations. Chromosome Res. 2, 137-145. doi: 10.1007/BF015534922

Kaelbling, M., and Fechheimer, N. S. (1985). Synaptonemal complex analysis of a pericentric inversion in chromosome 2 of domestic fowl, Gallus domesticus. Cytogenet. Genome Res. 39, 82-86. doi: 10.1159/0001321122

Kandul, N. P., Lukhtanov, V. A., and Pierce, N. E. (2007). Karyotypic diversity and speciation in Agrodiaetus butterflies. Evolution 61, 546-559. doi: 10.1111/j. 1558-5646.2007.00046.x

Key, K. H. L. (1968). The concept of stasipatric speciation. Syst. Biol. 17, 14-22. doi: 10.3390/insects2010049

King, M. (1993). Species Evolution: The Role of Chromosome Change. Cambridge: Cambridge University Press.

Kingswood, S. C., Kumamoto, A. T., Sudman, P. D., Fletcher, K. C., and Greenbaum, I. F. (1994). Meiosis in chromosomally heteromorphic goitered gazelle, Gazella subgutturosa (Artiodactyla, Bovidae). Chromosome Res. 2, $37-$ 46. doi: 10.1007/BF015394529

Kirkpatrick, M. (2010). How and why chromosome inversions evolve. PLoS Biol. 8:e1000501. doi: 10.1371/journal.pbio.1000501

Kirkpatrick, M. (2017). The evolution of genome structure by natural and sexual selection. J. Hered. 108, 3-11. doi: 10.1093/jhered/esw041

Kirkpatrick, M., and Barton, N. (2006). Chromosome inversions, local adaptation and speciation. Genetics 173, 419-434. doi: 10.1534/genetics.105.047985

Kulathinal, R. J., Stevison, L. S., and Noor, M. A. F. (2009). The genomics of speciation in Drosophila: diversity, divergence, and introgression estimated using low-coverage genome sequencing. PLoS Genet. 5:e1000550. doi: 10.1371/ journal.pgen.1000550

Lande, R. (1985). The fixation of chromosomal rearrangements in a subdivided population with local extinction and recolonisation. Heredity 54, 323-332. doi: 10.1038/hdy.1985.430

Larkin, D. M., Pape, G., Donthu, R., Auvil, L., Welge, M., and Lewin, H. A. (2009). Breakpoint regions and homologous synteny blocks in chromosomes have different evolutionary histories. Genome Res. 19, 770-777. doi: 10.1101/gr. 086546.108

Leaché, A. D., Banbury, B. L., Linkem, C. W., and de Oca, A. N. M. (2016). Phylogenomics of a rapid radiation: is chromosomal evolution linked to increased diversification in north american spiny lizards (Genus Sceloporus)? BMC Evol. Biol. 16:63. doi: 10.1186/s12862-016-0628-x

Lemaitre, C., Zaghloul, L., Sagot, M. F., Gautier, C., Arneodo, A., Tannier, E., et al. (2009). Analysis of fine-scale mammalian evolutionary breakpoints provides new insight into their relation to genome organisation. BMC Genomics 10:335. doi: 10.1186/1471-2164-10-335

Lindholm, A. K., Dyer, K. A., Firman, R. C., Fishman, L., Forstmeier, W., Holman, L., et al. (2016). The ecology and evolutionary dynamics of meiotic drive. Trends Ecol. Evol. 31, 315-326. doi: 10.1016/j.tree.2016. 02.001

Lohse, K., Clarke, M., Ritchie, M. G., and Etges, W. J. (2015). Genome-wide tests for introgression between cactophilic Drosophila implicate a role of inversions during speciation. Evolution 69, 1178-1190. doi: 10.1111/evo.12650

Lukhtanov, V. A., Kandul, N. P., Plotkin, J. B., Dantchenko, A. V., Haig, D., and Pierce, N. E. (2005). Reinforcement of pre-zygotic isolation and karyotype evolution in Agrodiaetus butterflies. Nature 436, 385-389. doi: 10.1038/ nature 03704

Malik, H. S., and Henikoff, S. (2003). Phylogenomics of the nucleosome. Nat. Struct. Mol. Biol. 10, 882-891. doi: 10.1038/nsb996
Mallet, J., Besansky, N., and Hahn, M. W. (2016). How reticulated are species? Bioessays 38, 140-149. doi: 10.1002/bies.201500149

Manterola, M., Page, J., Vasco, C., Berrios, S., Parra, M. T., Viera, A., et al. (2009). A high incidence of meiotic silencing of unsynapsed chromatin is not associated with substantial pachytene loss in heterozygous male mice carrying multiple simple Robertsonian translocations. PLoS Genet. 5:e1000625. doi: 10.1371/ journal.pgen.1000625

Martin, S. H., Davey, J. W., and Jiggins, C. D. (2015). Evaluating the use of ABBABABA statistics to locate introgressed loci. Mol. Biol. Evol. 32, 244-257. doi: $10.1093 / \mathrm{molbev} / \mathrm{msu} 269$

Maynes, G. M. (1989). “Zoogeography of the Macropodoidea” in Kangaroos, Wallabies and Rat-Kangaroos, 1st Edn, ed. G. Grigg, P. Jarman, and I. Hume (Chipping Norton, NSW: Surrey Beatty \& Sons Pty, Ltd.), 47-66.

McGaugh, S. E., and Noor, M. A. F. (2012). Genomic impacts of chromosomal inversions in parapatric Drosophila species. Philos. Trans. R. Soc. Lond. B Biol. Sci. 367, 422-429. doi: 10.1098/rstb.2011.0250

Mihola, O., Trachtulec, Z., Vlcek, C., Schimenti, J. C., and Forejt, J. (2009). A mouse speciation gene encodes a meiotic histone H3 methyltransferase. Science 323, 373-375. doi: 10.1126/science.1163601

Molina, W. F., Martinez, P. A., Bertollo, L. A. C., and Bidau, C. J. (2014). Evidence for meiotic drive as an explanation for karyotype changes in fishes. Mar. Genomics 15, 29-34. doi: 10.1016/j.margen.2014.05.001

Muller, H. (1942). Isolating mechanisms, evolution and temperature. Biol. Symp. 6, $71-125$.

Muller, H. J. (1930). Types of visible variations induced by X-rays in Drosophila. J. Genet. 22, 299-334. doi: 10.1007/BF02984195

Nachman, M. W., and Searle, J. B. (1995). Why is the house mouse karyotype so variable? Trends Ecol. Evol. 10, 397-402. doi: 10.1016/S0169-5347(00) 89155-7

Nakhleh, L. (2013). Computational approaches to species phylogeny inference and gene tree reconciliation. Trends Ecol. Evol. 28, 719-728. doi: 10.1016/j.tree.2013. 09.004

Nam, K., Munch, K., Hobolth, A., Dutheil, J. Y., Veeramah, K., Woerner, A., et al. (2014). Strong Selective Sweeps Associated with Ampliconic Regions in Great Ape X Chromosomes. Available at: https://arxiv.org/abs/1402.5790

Nater, A., Burri, R., Kawakami, T., Smeds, L., and Ellegren, H. (2015). Resolving evolutionary relationships in closely related species with whole-genome sequencing data. Syst. Biol. 64, 1000-1017. doi: 10.1093/sysbio/syv045

Navarro, A., and Barton, N. H. (2003). Accumulating postzygotic isolation in parapatry: a new twist on chromosomal speciation. Evolution 57, 447-459. doi: 10.1111/j.0014-3820.2003.tb01537.x

Neale, M. J., and Keeney, S. (2006). Clarifying the mechanics of DNA strand exchange in meiotic recombination. Nature 442, 153-158. doi: 10.1038/ nature 04885

Nei, M., Kojima, K. I., and Schaffer, H. E. (1967). Frequency changes of new inversions in populations under mutation-selection equilibria. Genetics 57, $741-750$.

Noor, M. A., and Bennett, S. M. (2009). Islands of speciation or mirages in the desert? Examining the role of restricted recombination in maintaining species. Heredity 103, 439-444. doi: 10.1038/hdy.2009.151

Noor, M. A., Grams, K. L., Bertucci, L. A., and Reiland, J. (2001). Chromosomal inversions and the reproductive isolation of species. Proc. Natl. Acad. Sci. U.S.A. 98, 12084-12088. doi: 10.1073/pnas.221274498

O'Neill, R. W., Eldridge, M. D. B., Toder, R., Ferguson-Smith, M. A., O'Brien, P. C., and Graves, J. A. M. (1999). Chromosome evolution in kangaroos (Marsupialia: Macropodidae): cross species chromosome painting between the tammar wallaby and rock wallaby spp. with the $2 n=22$ ancestral macropodid karyotype. Genome 42, 525-530. doi: 10.1139/g98-159

O’Neill, R. J., Eldridge, M. D. B., and Metcalfe, C. J. (2004). Centromere dynamics and chromosome evolution in marsupials. J. Hered. 95, 375-381. doi: 10.1093/ jhered/esh063

Ortiz-Barrientos, D., Engelstädter, J., and Rieseberg, L. H. (2016). Recombination rate evolution and the origin of species. Trends Ecol. Evol. 31, 226-236. doi: 10.1016/j.tree.2015.12.016

Pardo-Manuel de Villena, F., and Sapienza, C. (2001). Female meiosis drives karyotypic evolution in mammals. Genetics 159, 1179-1189.

Payseur, B. A., and Rieseberg, L. H. (2016). A genomic perspective on hybridization and speciation. Mol. Ecol. 25, 2337-2360. doi: 10.1111/mec.13557 
Peischl, S., Koch, E., Guerrero, R. F., and Kirkpatrick, M. (2013). A sequential coalescent algorithm for chromosomal inversions. Heredity 111, 200-209. doi: 10.1038/hdy. 2013.38

Pennell, M. W., Kirkpatrick, M., Otto, S. P., Vamosi, J. C., Peichel, C. L., Valenzuela, N., et al. (2015). Y fuse? Sex chromosome fusions in fishes and reptiles. PLoS Genet. 11:e1005237. doi: 10.1371/journal.pgen.1005237

Pinho, C., and Hey, J. (2010). Divergence with gene flow: models and data. Annu. Rev. Ecol. Evol. Syst. 41, 215-230. doi: 10.1146/annurev-ecolsys-102209-144644

Pokorná, M., Altmanová, M., and Kratochvíl, L. (2014). Multiple sex chromosomes in the light of female meiotic drive in amniote vertebrates. Chromosome Res. 22, 35-44. doi: 10.1007/s10577-014-9403-2

Polyakov, A. V., White, T. A., Jones, R. M., Borodin, P. M., and Searle, J. B. (2011). Natural hybridization between extremely divergent chromosomal races of the common shrew (Sorex araneus, Soricidae, Soricomorpha): hybrid zone in Siberia. J. Evol. Biol. 24, 1393-1402. doi: 10.1111/j.1420-9101.2011. 02266.x

Pope, L. C., Sharp, A., and Moritz, C. (1996). Population structure of the yellowfooted rock-wallaby Petrogale xanthopus (Gray, 1854) inferred from mtDNA sequences and microsatellite loci. Mol. Ecol. 5, 629-640. doi: 10.1111/j.1365294X.1996.tb00358.x6

Potter, S., Cooper, S. J., Metcalfe, C. J., Taggart, D. A., and Eldridge, M. D. B. (2012a). Phylogenetic relationships of rock-wallabies Petrogale (Marsupialia: Macropodidae) and their biogeographic history within Australia. Mol. Phylogenet. Evol. 62, 640-652. doi: 10.1016/j.ympev.2011.11.005

Potter, S., Eldridge, M. D. B., Taggart, D. A., and Cooper, S. J. B. (2012b). Multiple biogeographical barriers identified across the monsoon tropics of northern Australia: phylogeographic analysis of the brachyotis group of rock-wallabies. Mol. Ecol. 21, 2254-2269. doi: 10.1111/j.1365-294X.2012.05523.x

Potter, S., Moritz, C., and Eldridge, M. D. B. (2015). Gene flow despite complex Robertsonian fusions among rock-wallaby (Petrogale) species. Biol. Lett. 11:20150731. doi: 10.1098/rsbl.2015.0731

Prado-Martinez, J., Sudmant, P. H., Kidd, J. M., Li, H., Kelley, J. L., LorenteGaldos, B., et al. (2013). Great ape genetic diversity and population history. Nature 499, 471-475. doi: 10.1038/nature12228

Presgraves, D. C. (2008). Sex chromosomes and speciation in Drosophila. Trends Genet. 24, 336-343. doi: 10.1016/j.tig.2008.04.007

Presgraves, D. C. (2010). Darwin and the origin of interspecific genetic incompatibilities. Am. Nat. 176, S45-S60. doi: 10.1086/657058

Putnam, N. H., O’Connell, B. L., Stites, J. C., Rice, B. J., Blanchette, M., Calef, R., et al. (2016). Chromosome-scale shotgun assembly using an in vitro method for long-range linkage. Genome Res. 26, 342-350. doi: 10.1101/gr.193 474.115

Qi, J., Chen, Y., Copenhaver, G P., and Ma, H. (2014). Detection of genomic variations and DNA polymorphisms and impact on analysis of meiotic recombination and genetic mapping. Proc. Natl. Acad. Sci. U.S.A. 111, 1000710012. doi: 10.1073/pnas.1321897111

Rasmussen, M. D., Hubisz, M. J., Gronau, I., and Siepel, A. (2014). Genomewide inference of ancestral recombination graphs. PLoS Genet. 10:e1004342. doi: 10.1371/journal.pgen.1004342

Rieseberg, L. H. (2001). Chromosomal rearrangements and speciation. Trends Ecol. Evol. 16, 351-358. doi: 10.1016/S0169-5347(01)02187-5

Rofe, R., and Hayman, D. (1985). G-banding evidence for a conserved complement in Marsupialia. Cytogenet. Cell Genet. 39, 40-50. doi: 10.1159/00013 21018

Rofe, R. H. (1979). G-Banding and Chromosome Evolution in Marsupials. Ph.D. thesis, University of Adelaide, Adelaide SA.

Ruiz-Herrera, A., Castresana, J., and Robinson, T. J. (2006). Is mammalian chromosomal evolution driven by regions of genome fragility? Genome Biol. 7:R115. doi: 10.1186/gb-2006-7-12-r115

Saether, S. A., Saether, G. P., Borge, T., Wiley, C., Svedin, N., Andersson, G., et al. (2007). Sex chromosome-linked species recognition and evolution of reproductive isolation in flycatchers. Science 318, 95-97. doi: 10.1126/science. 1141506

Sawamura, K., Ting, C.-T., Kopp, A., and Moyle, L. C. (2012). Mechanisms of Speciation. Int. J. Evol. Biol. 2012:820358. doi: 10.1155/2012/820358

Sharman, G. B., Close, R. L., and Maynes, G. M. (1990). Chromosomal evolution, phylogeny and speciation of rock wallabies (Petrogale: Macropodidae). Aust. J. Zool. 37, 351-363.
Shaw, D. D., Coates, D. J., and Wilkinson, P. (1986). Estimating the genic and chromosomal components of reproductive isolation within and between subspecies of the grasshopper Caledia captiva. Can. J. Genet. Cytol. 28, 686-695. doi: 10.1139/g86-098

Shiu, P. K. T., Raju, N. B., Zickler, D., and Metzenberg, R. L. (2001). Meiotic silencing by unpaired DNA. Cell 107, 905-916. doi: 10.1016/S0092-8674(01) 00609-2

Sites, J. W., and Moritz, C. (1987). Chromosomal evolution and speciation revisited. Syst. Zool. 36, 153-174. doi: 10.2307/2413266

Slijepcevic, P. (1998). Telomeres and mechanisms of Robertsonian fusion. Chromosoma 107, 136-140. doi: 10.1007/s0041200502892

Smagulova, F., Gregoretti, I. V., Brick, K., Khil, P., Camerini-Otero, R. D., and Petukhova, G. V. (2011). Genome-wide analysis reveals novel molecular features of mouse recombination hotspots. Nature 472, 375-378. doi: 10.1038/ nature09869

Solis-Lemus, C., Yang, M., and Ané, C. (2016). Inconsistency of species-tree methods under gene flow. Syst. Biol. 65, 843-851. doi: 10.1093/sysbio/syw030

Spirito, F. (1998). “The role of chromosomal rearrangements in speciation," Endless Forms, ed. D. J. Howard and S. H. Berlocher (Oxford: Oxford University Press), 320-329.

Stebbins, G. L. (1950). Variation and Evolution in Plants. New York, NY: Columbia University Press.

Sturtevant, A. H. (1938). Essays on evolution. III. On the origin of interspecific sterility. Q. Rev. Biol. 13, 333-335. doi: 10.1086/394565

Suh, A. (2016). The phylogenomic forest of bird trees contains a hard polytomy at the root of Neoaves. Zool. Scripta 45, 50-62. doi: 10.1111/zsc.12213

Templeton, A. R. (1981). Mechanisms of speciation-a population genetics approach. Annu. Rev. Ecol. Syst. 12, 23-48. doi: 10.1146/annurev.es.12.110181. 000323

Than, C., Ruths, D., and Nakhleh, L. (2008). PhyloNet: a software package for analyzing and reconstructing reticulate evolutionary histories. $B M C$ Bioinformatics 9:322. doi: 10.1186/1471-2105-9-322

Torgasheva, A. A., and Borodin, P. M. (2010). Synapsis and recombination in inversion heterozygotes. Biochem. Soc. Trans. 38, 1676-1680. doi: 10.1042/ BST0381676

Turelli, M. (1998). The causes of Haldane's rule. Science 282, 889-891. doi: 10.1126/ science.282.5390.889

Turelli, M., and Moyle, L. C. (2007). Asymmetric postmating isolation: Darwin's corollary to Haldane's rule. Genetics 176, 1059-1088. doi: 10.1534/genetics.106. 065979

Turner, J. M. (2007). Meiotic sex chromosome inactivation. Development 134, 1823-1831. doi: 10.1242/dev.000018

Ullastres, A., Farré, M., Capilla, L., and Ruiz-Herrera, A. (2014). Unraveling the effect of genomic structural changes in the rhesus macaque-implications for the adaptive role of inversions. BMC Genomics 15:530. doi: 10.1186/1471-2164-15530

Vozdova, M., Sebestova, H., Kubickova, S., Cernohorska, H., Awadova, T., Vahala, J., et al. (2014). Impact of Robertsonian translocation on meiosis and reproduction: an impala (Aepyceros melampus) model. J. Appl. Genet. 55, 249-258. doi: 10.1007/s13353-014-0193-1

Walsh, J. B. (1982). Rate of accumulation of reproductive isolation by chromosome rearrangements. Am. Nat. 120, 510-532. doi: 10.1086/284008

Wen, D., Yu, Y., Hahn, M. W., and Nakhleh, L. (2016). Reticulate evolutionary history and extensive introgression in mosquito species revealed by phylogenetic network analysis. Mol. Ecol. 25, 2361-2372. doi: 10.1111/mec. 13544

Wesche, P. L., and Robinson, T. J. (2012). Different patterns of Robertsonian fusion pairing in Bovidae and the house mouse: the relationship between chromosome size and nuclear territories. Genet. Res. 94, 97-111. doi: 10.1017/ S0016672312000262

White, M. J. D. (1973). Animal Cytology and Evolution. Cambridge: Cambridge University Press.

White, M. J. D. (1978). Modes of Speciation. San Francisco, CA: W. H. Freeman.

Wright, S. (1982). The shifting balance theory and macroevolution. Annu. Rev. Genet. 16, 1-20. doi: 10.1146/annurev.ge.16.120182.000245

Wyttenbach, A., Borodin, P., and Hausser, J. (1998). Meiotic drive favors Robertsonian metacentric chromosomes in the common shrew (Sorex araneus, Insectivora, Mammalia). Cytogenet. Genome Res. 83, 199-206. 
Yannic, G., Basset, P., and Hausser, J. (2009). Chromosomal rearrangements and gene flow over time in an inter-specific hybrid zone of the Sorex araneus group. Heredity 102, 616-625. doi: 10.1038/hdy.2009.19

Yoshida, K., and Kitano, J. (2012). The contribution of female meiotic drive to the evolution of neo-sex chromosomes. Evolution 66, 3198-3208. doi: 10.1111/ j.1558-5646.2012.01681.x

Yu, Y., Dong, J., Liu, K., and Nakhleh, L. (2014). Maximum likelihood inference of reticulate evolutionary histories. Proc. Natl. Acad. Sci. U.S.A. 111, 16448-16453. doi: 10.1073/pnas.1407950111

Yu, Y., Ristic, N., and Nakhleh, L. (2013). Fast algorithms and heuristics for phylogenomics under hybridization and incomplete lineage sorting. BMC Bioinformatics 14:S6. doi: 10.1186/1471-2105-14-S15-S6

Zickler, D., and Kleckner, N. (1999). Meiotic chromosomes: integrating structure and function. Annu. Rev. Genet. 33, 603-754. doi: 10.1146/annurev.genet.33. 1.603
Conflict of Interest Statement: The handling Editor declared a shared affiliation, though no other collaboration, with one of the authors JD and states that the process nevertheless met the standards of a fair and objective review.

The other authors declare that the research was conducted in the absence of any commercial or financial relationships that could be construed as a potential conflict of interest.

Copyright (C) 2017 Potter, Bragg, Blom, Deakin, Kirkpatrick, Eldridge and Moritz. This is an open-access article distributed under the terms of the Creative Commons Attribution License (CC BY). The use, distribution or reproduction in other forums is permitted, provided the original author(s) or licensor are credited and that the original publication in this journal is cited, in accordance with accepted academic practice. No use, distribution or reproduction is permitted which does not comply with these terms. 